(C) <2019>. This manuscript version is made available under the CC-BY-NC-ND 4.0 license https://creativecommons.org/licenses/by-nc-nd/4.0/

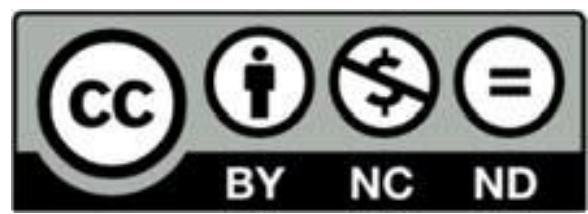

Accepted version.

This paper was published as: Harris-Lovett, S., Lienert, J., Sedlak, D. L. (2019) A mixed-methods approach to strategic planning for multi-benefit regional water infrastructure.

Journal of Environmental Management 233: 218-237. https://doi.org/10.1016/j.jenvman.2018.11.112.

\title{
A Mixed-Methods Approach to Strategic Planning for Multi-Benefit Regional Water Infrastructure
}

\author{
Sasha Harris-Lovett ${ }^{1,3 *}$, Judit Lienert ${ }^{2}$, and David Sedlak ${ }^{3,4}$ \\ ${ }^{1}$ Energy and Resources Group, University of California, Berkeley \\ ${ }^{2}$ Eawag: Swiss Federal Institute of Aquatic Science and Technology \\ ${ }^{3}$ Engineering Research Center for Reinventing the Nation's Urban Water Infrastructure \\ (ReNUWIt) \\ ${ }^{4}$ Department of Civil and Environmental Engineering, University of California, Berkeley
}

\section{Highlights:}

- A mixed-methods approach supports strategic planning for multi-benefit water infrastructure.

- These methods identify agreements between stakeholders to aid decision-makers.

- They clarify relative effects of future uncertainties and technical uncertainties on outcomes.

*Corresponding author: Sasha Harris-Lovett (sharrislovett@berkeley.edu) 
Accepted manuscript: Harris-Lovett, S., Lienert, J., Sedlak, D. L. (2019) A mixed-methods approach to strategic planning for multi-benefit regional water infrastructure. Journal of Environmental Management 233: 218-237. https://doi.org/10.1016/i.jenvman.2018.11.112.

Keywords: multi-criteria decision analysis, regional environmental planning, nutrient management, wastewater treatment, stakeholder analysis

Abstract: Finding regional solutions for water infrastructure and other environmental management challenges requires coordination, communication, and a shared understanding among different stakeholders. To develop a more versatile and collaborative decision-making process for nutrient management in the San Francisco Bay Area, we used a mixed-methods approach consisting of stakeholder analysis with cluster analysis, multi-criteria decision analysis (MCDA), and scenario planning. These methods allowed us to identify agreements and disagreements in stakeholder objectives and preferences, clarify ways in which different options could meet the goals of diverse stakeholders, and elucidate how scientific uncertainty about technical performance and future conditions could affect management strategies. Results of the analysis indicate that several non-conventional nutrient management options like constructed wetlands and increased water recycling for irrigation met the goals of many stakeholders under a variety of future scenarios. A comparison of MCDA results with a more traditional 'costefficiency' measure (i.e., optimizing for the lowest cost per mass of nutrients removed) revealed little correlation between the two methods for stakeholders who expressed a preference for cobenefits of management options such as increased water supply and nutrient recovery for fertilizer use. The method also allowed us to identify key areas of disagreement (e.g., the relative importance of constructing infrastructure that would not be affected by sea level rise) that should find regulatory or professional consensus before advancing with decision-making. This mixedmethods approach is time-consuming and requires specific expertise that is not always available to stakeholders. The development of more efficient preference elicitation and interaction procedures would increase the likelihood that decision-makers would make the extra effort required to use this potentially powerful method. Nonetheless, the mixed-methods approach had several important advantages over more traditional strategic planning methods including its ability to stimulate discussions amongst stakeholders who do not regularly interact, support collaborative planning, and encourage multi-benefit solutions.

\section{Introduction}

There is increasing interest amongst researchers and practitioners in improving urban water management by transitioning from existing, segmented management approaches to integrated, multi-benefit approaches (Brown and Farrelly, 2009; Larsen and Gujer, 1997). Achieving this goal is socially, politically, and technically complex because water infrastructure affects many different stakeholders, lasts for multiple decades, and requires significant financial investment. Improved strategic planning processes can help facilitate this transition by allowing stakeholders to articulate their values and objectives, by considering innovative options, and by explicitly accounting for uncertainties about the future (Truffer et al., 2010). They also can support major shifts in water infrastructure investment by allowing decision-makers to consider the long-term benefits of potential systems in ways that are not captured by existing planning methods, which often result in incremental improvements (Dominguez et al., 2009).

To facilitate transitions to multi-benefit water infrastructure, decision-makers must engage with stakeholders who have historically been excluded from the decision-making process, for example, coastal land managers in the case of planning for wastewater infrastructure (Pearson et al., 2010). Researchers have developed qualitative strategic planning processes in which stakeholders describe uncertainties and qualitatively explore trade-offs amongst different 
Accepted manuscript: Harris-Lovett, S., Lienert, J., Sedlak, D. L. (2019) A mixed-methods approach to strategic planning for multi-benefit regional water infrastructure. Journal of Environmental Management 233: 218-237. https://doi.org/10.1016/i.jenvman.2018.11.112.

management alternatives (Störmer et al., 2009; Störmer and Truffer, 2009). This can include analysis of the social dynamics and long-term goals of stakeholders (Dominguez et al., 2011). Yet researchers suggest that decision-makers whose choices implicate large sums of money or influence many peoples' lives should use both qualitative and quantitative data to inform decision-making (Mays et al., 2005; Pope and Mays, 1995; Munda et al., 1994). In particular, transitions towards more sustainable urban water infrastructure are best supported by qualitative analyses of actors, networks, and institutions paired with scientific modeling, because decisionmaking needs to consider both social and physical aspects of the available options (Fratini et al., 2012). Therefore a mixed-methods approach is useful (Greening and Bernow, 2004).

Due to the long design lifetimes of most water infrastructure projects, considering future conditions is essential for decision-making. Scenario planning includes critical uncertainties about the future when analyzing potential management options. This tool allows decision-makers to explicitly consider a range of possible future conditions, and is becoming more popular among water infrastructure planning professionals (Kang and Lansey, 2012; Lienert et al., 2006) as well as within environmental management (Mahmoud et al., 2009; Peterson et al., 2003).

In addition to scenario planning, multi-criteria decision analysis (MCDA) can also guide environmental management (Huang et al., 2011; Liu et al., 2008; Reed, 2008; Mendoza and Martins, 2006; Linkov et al., 2006), water resources management (Kunz et al., 2013; Mutikanga et al., 2011; Marttunen and Hämäläinen, 2008; Gregory et al., 2006; Hajkowicz and Collins, 2006; Borsuk et al., 2001), and water infrastructure development (Baserba et al., 2016; Zheng et al., 2016; Scholten et al., 2015; Kabir et al., 2014; Lienert et al., 2014, 2006; Garrido- Hauger et al., 2002; Al-Kloub et al., 1997). MCDA creates a structured framework for multiple objectives articulated by local stakeholders (Belton and Stewart, 2002; Keeney, 1992). Participating in MCDA interviews can help decision-makers clarify their own objectives for any given decision (Marttunen and Hämäläinen, 2008; Lichtenstein and Slovic, 2006; Gregory et al., 2001; Payne et al., 1992). This clarity is especially important for infrastructure projects because it promotes transparency in uses of public funds (McDaniels et al., 1999). By identifying the topics of greatest (dis-)agreement amongst stakeholders, MCDA can help avoid later conflicts (Hajkowicz, 2008; Hermans et al., 2007).

An MCDA framework effectively parses out the relative importance of stakeholder preferences from assessment of the technical performance of management options (Marttunen and Hämäläinen, 2008; Bojórquez-Tapia et al., 2005; Matsatsinis and Samaras, 2001). This distinction focuses discussion on objectives of the projects ("what is important") rather than on discrete management options ("how to achieve objectives"; Greening and Bernow, 2004; Lai et al., 2002). This facilitates considering innovative options that would not result from incremental improvements to existing infrastructure. Specifically, to create an overall ranking of options, MCDA helps identify the tradeoffs between achievement of objectives among different options (Gregory et al., 2001). This allows decision-makers to explicitly weigh trade-offs between social, cultural, environmental, and economic factors which may not be captured in traditional monetary analyses (Kiker et al., 2005).

Combinations of MCDA with other strategic planning methods (i.e., mixed-methods approach) are considered important for expanded research in natural resources management (Kangas et al., 2002). Here, we combine stakeholder and scenario analysis with MCDA to provide decision support and facilitate strategic planning for nutrient management in the San Francisco Bay Area. This study extends previous mixed-methods approaches that have considered a range of uncertain future conditions, like population growth and climate change in 
Accepted manuscript: Harris-Lovett, S., Lienert, J., Sedlak, D. L. (2019) A mixed-methods approach to strategic planning for multi-benefit regional water infrastructure. Journal of Environmental Management 233: 218-237. https://doi.org/10.1016/i.jenvman.2018.11.112.

multi-criteria decision analysis for water infrastructure planning (Zheng et al., 2016; Lienert et al., 2014). This mixed-methods approach is more broadly relevant for environmental management decisions characterized by problems that involve many stakeholders, require regional solutions and involve significant capital investments for long-term infrastructure.

\subsection{Case Study: Nitrogen Management in the San Francisco Bay}

Many estuaries and coastal waters are adversely impacted by nitrogen pollution (Howarth, 2008; Howarth et al., 2002, 2000). Excess nutrients can cause oxygen depletion and eutrophication, reduce fisheries productivity and decrease recreational value (Dodds et al., 2008). Excessive nutrients discharges to surface waters can also result in growth of algae that exude harmful toxins (Heisler et al., 2008; Anderson et al., 2002; Van Dolah, 2000). Nitrogen pollution problems are complex, with unclear, context-dependent results to any given solution, and have been termed "wicked" problems (DeFries and Nagendra, 2017; Thornton et al., 2013).

Nutrient management in the San Francisco Bay Area exhibits many characteristics of complex environmental management decisions that are well-suited for a mixed-methods approach. Decision-makers must balance concerns about human effects on ecosystems, costs, and numerous human interactions (Benda et al., 2002). The decision-making process is complicated by scientific uncertainty over the long term, differing stakeholder opinions, and the need for regional solutions (Balint et al., 2011).

The San Francisco Bay ecosystem has historically been insensitive to nitrogen pollution, likely because algal growth was light-limited due to high levels of suspended particles associated with hydraulic mining in the nineteenth century and water diversion projects built in the twentieth century (Cloern, 1999; Alpine and Cloern, 1988; Cole and Cloern, 1984). As the turbidity of the Bay declines and nitrogen levels increase with population growth (Cloern and Jassby, 2012), evidence indicates that algal growth is shifting from light- to nitrogen-limited (Cloern, 1999; Boynton et al., 1982). The extent of the impacts associated with nitrogen pollution are uncertain, especially when considering the effects of climate change and invasive species (Sutula and Senn, 2015).

Presently, most of the nitrogen entering the San Francisco Bay estuary ("the Bay") is associated with urban and agricultural runoff and the discharge of municipal wastewater treatment plants (Novick and Senn, 2014; Wankel et al., 2005; Hager and Schemel, 1992). South of the Bay Bridge, more than $90 \%$ of the anthropogenic nitrogen load is attributable to the discharge of municipal wastewater effluent (Novick and Senn, 2014) (Figure 1). 


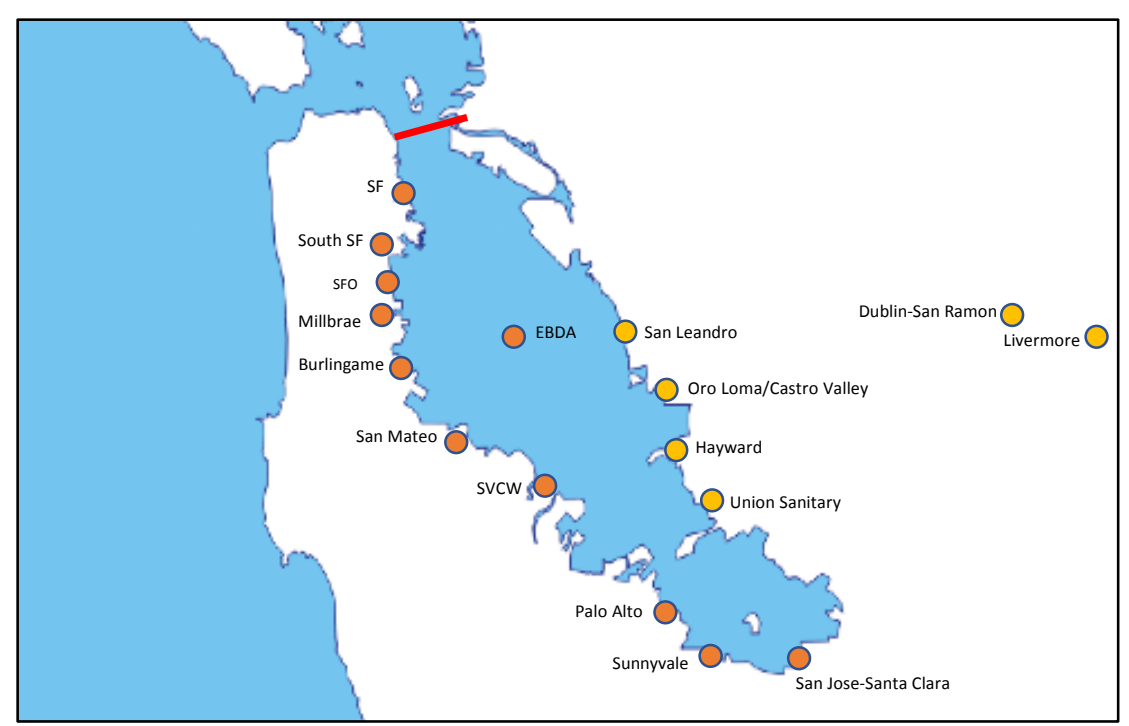

Figure 1. Red dots mark wastewater treatment discharge locations to the southern reach of the San Francisco Bay. SF: San Francisco; SFO: San Francisco Airport; SVCW: Silicon Valley Clean Water; EBDA: East Bay Dischargers Authority. Yellow dots mark facilities that currently discharge effluent via the EBDA outfall pipe. Red line marks the Bay Bridge. (Base image $\odot \mathrm{d}$ maps.com/Wikimedia Commons/2017)

In response to the potential for future regulatory action to control nitrogen loads (San Francisco Bay Regional Water Quality Control Board, 2014), a varied group of stakeholders have begun to plan strategies to lower nutrient loads (primarily nitrogen) to the Bay. The Nutrient Management Strategy team is advised by a steering committee, a stakeholder advisory group, a technical working group, and a science team (San Francisco Bay Nutrient Management Strategy, 2016).

Although controlling nutrient loads has been viewed traditionally to concern mainly two sets of stakeholders - the regulators (San Francisco Regional Water Quality Control Board, US Environmental Protection Agency) and the nutrient dischargers (municipal wastewater treatment plants), reality is more complex. There is a strong interest in the region for providing nitrogen control infrastructure that also provides other benefits. These co-benefits include increased shoreline habitat, recreational shoreline access, water supply, and resilience to sea level rise (Harris-Lovett et al., 2018). Therefore, strategies to manage nitrogen loads in the Bay Area may also affect other stakeholders like water supply managers, baylands land managers, and ecological stewards.

Unlike situations in which MCDA has been employed to find a single optimal solution (e.g. choosing a location for an airport; Bojórquez-Tapia et al., 2005), the diverse set of stakeholders in the San Francisco Bay must make a series of separate decisions that will advance collective goals. Wastewater treatment plant managers (dischargers) are obliged to preserve water quality while respecting the financial limitations of the ratepayers of treatment plants (Harris-Lovett et al., 2018). Each discharger must decide which technologies to employ or actions to take (if any) to control the mass of nutrients released in their effluent. Regulators must enforce laws and policies to protect the Bay ecosystem (e.g., Federal Water Pollution Control Act, 33 U.S.C. 1251-1376), so their decisions entail whether and how to set legal limits on nutrient loading. Other stakeholders, like baylands stewards, coastal planners, or environmental advocates, can decide whether to contest such decisions through litigation. 
Within this varied decision-making context, MCDA on its own is not sufficient for providing regional strategic planning support. This issue, like other "wicked" problems of ecosystem management, requires decision support tools to facilitate multi-sector decisionmaking, enable collaborative decision-making across agencies and administrative boundaries, and balance different stakeholder values (DeFries and Nagendra, 2017). Hereby, strategic planning endeavors to facilitate greater understanding and teamwork amongst diverse stakeholders without necessarily aiming for consensus or a one-size-fits-all solution.

To provide this support, we combined stakeholder analysis and scenario planning with multicriteria decision analysis. We evaluate the insights derived from this mixed-methods approach and generalize its applicability to strategic water infrastructure planning and management of complex environmental problems. To support decision-making about nutrient management in San Francisco Bay, we addressed the following specific aims:

1. Identify the objectives on which stakeholders agree and disagree, and clarify key areas where consensus should be achieved before decision-making proceeds.

2. Assess the value of different nutrient management options with respect to stakeholder objectives.

3. Define and bound the uncertainties associated with technical performance and future conditions for each management option. Determine which options perform most robustly under a range of future scenarios and across stakeholder viewpoints.

4. Determine areas in which further scientific research would be helpful in informing decision-making.

\section{Materials and Methods}

\subsection{Methodological overview}

The research proceeded in several stages. (1) First, we selected stakeholders for participation in interviews. Initial interviews included a broad array of 32 stakeholders. Since follow-up interviews required a significant time investment from the participants and because it would be prohibitively complex to present 32 stakeholder results in an MCDA, we used (2) cluster analysis to group stakeholders. This cluster analysis ensured selecting stakeholders with high relevance to decision-making and representing a broad range of diverse viewpoints; the two most important aspects for participation in a (3) follow-up MCDA preference weighting interview. Data from the second interviews about stakeholder preferences and ideas for potential management solutions informed (4) a multi-criteria decision analysis to determine the relative value of various management options. Stakeholder interview data also informed (5) future scenarios, which were (6) paired with MCDA to determine ways in which management options' value changed under uncertain future conditions. Each step of the research process is detailed below.

\subsection{Stakeholder selection}

Stakeholders were identified based on their professional interest and expertise in nutrient loading to San Francisco Bay, specifically whether they were involved with decision-making or would be affected by decisions made (Reed et al., 2009; Grimble and Wellard, 1997). Stakeholders were chosen to represent diverse groups of regulators, wastewater managers, coastal stewards, researchers, and advocates (for environmental or industrial causes). These stakeholders go far beyond the dischargers and regulators who historically have made decisions about wastewater infrastructure. Although wastewater infrastructure affects all people in the region, wastewater has typically been considered "out-of-sight, out-of-mind" by the general 
Accepted manuscript: Harris-Lovett, S., Lienert, J., Sedlak, D. L. (2019) A mixed-methods approach to strategic planning for multi-benefit regional water infrastructure. Journal of Environmental Management 233: 218-237. https://doi.org/10.1016/i.jenvman.2018.11.112.

population in California (Harris-Lovett and Sedlak, 2015). For this reason, only those with professional (not personal) interest were chosen as stakeholders.

Stakeholder identification proceeded in three iterative stages:

1.) We identified organizations and individuals involved with decision-making about nutrient management as evidenced by their presence on relevant advisory committees (e.g., Nutrient Management Strategy), by appearances at relevant public meetings (records of attendees), or by authorship of relevant documents. When an organization (and no particular person within it) was identified, the person within the organization with the most responsibility for strategic planning was contacted using publiclyavailable professional email addresses and asked to participate or to recommend someone within the organization to participate.

2.) Once interviews commenced (see Section 2.3), we used snowball sampling (Atkinson and Flint, 2001; Biernacki and Waldorf, 1981) to identify other stakeholders. Additionally, participants were asked to rate their own influence over decisionmaking as well the extent to which decisions about nutrients would affect them, on a scale of 1-7. They also rated the influence and defined the extent to which others would be affected (see approach in Lienert et al., 2013). Multiple stakeholders from a single organization were contacted when they had distinct roles in decision-making and when they were specifically identified by other stakeholders.

3.) The researchers determined stakeholders who would be affected by proposed nutrient management options, which were described in regional planning documents and discussed in initial interviews. For example, references to upgrading treatment plants to include biological nutrient removal technologies (e.g., San Francisco Bay Regional Water Quality Control Board, 2014), resulted in including stakeholders from engineering consulting companies who would conduct the work. Constructing wetlands for nutrient removal (e.g., Wren, 2017) resulted in including coastal land managers.

\subsection{Initial interviews}

Initial interviews were designed to collect data for:

1.) Conducting a stakeholder analysis that illuminated the history and current state of decision-making about nutrients.

2.) Building an objectives hierarchy for the MCDA.

3.) Defining attributes for the decision criteria in the MCDA.

4.) Developing ideas for nutrient management options.

5.) Determining critical future uncertainties to test in the MCDA.

6.) Increasing understanding of how nutrient management fit into other long-term planning objectives for the estuary and into stakeholders' professional mandates (see Harris-Lovett et al., 2018).

Initial interviews were semi-structured. Open-ended questions were designed to elicit the interest of stakeholders in nutrient management in San Francisco Bay and their role in decisionmaking. We asked for their objectives for good nutrient management and their ideas for ways to measure fulfillment of these objectives (the 'attributes' for MCDA). We also elicited their ideas for potential nutrient management options and their impressions of future conditions that might affect nutrient management (see interview guidelines in Supplemental Information, Figure S1). 
Accepted manuscript: Harris-Lovett, S., Lienert, J., Sedlak, D. L. (2019) A mixed-methods approach to strategic planning for multi-benefit regional water infrastructure. Journal of Environmental Management 233: 218-237. https://doi.org/10.1016/i.jenvman.2018.11.112.

First round interviews lasted 30 to 90 minutes and were conducted by telephone, with the exception of four individuals from one organization who were interviewed in person together. Prior to their interview, these four individually completed handouts to elicit individual points of view; the entire group then engaged in discussion. All interviews were transcribed and coded for themes pertaining to the aims of the interview (listed above) using MaxQDA software, version 12.3.2. The software was manufactured by VERBI Software GmbH, based in Berlin, Germany, and purchased online at www.maxqda.com.

The interview protocol was approved by the Committee for Protection of Human Subjects (the Institutional Review Board) at the University of California, Berkeley.

\subsection{Development of objectives hierarchy and attributes}

Synthesizing information from the first-round interviews, we developed a hierarchy of fundamental objectives (Eisenführ et al., 2010) for decision-making about nutrient management in San Francisco Bay, along with attributes to measure each objective. A top-level fundamental objective served as an umbrella for a similar number of fundamental sub-objectives ( 2 or 3 ). This balanced grouping in hierarchy branches minimized splitting biases (Hämäläinen and Alaja, 2008). Overarching goals for good nutrient management were informed by previous MCDA analysis of water infrastructure planning (Lienert et al., 2014).

Attributes were chosen to measure how well different management options fulfilled each objective. We attempted to choose attributes that directly related to the objectives, that could reasonably be determined for each option, and were understandable, comprehensive, and unambiguous. These characteristics are considered best-practice for attribute selection in MCDA (Eisenführ et al., 2010). However, these best practices for attribute selection could not always be fulfilled; in some instances there was no clear consensus from stakeholders on how to measure fulfillment of an objective. This necessitated selecting an attribute informed by consultation with specialists. One example was "good water quality": some stakeholders stated that this objective should be assessed by probability of impairment, others indicated that it would be met only in the absence of impairment, and others indicated that a proxy measure, like abnormally low concentrations of dissolved oxygen or high concentrations of chlorophyll-a would indicate a failure to meet the objective. After consulting with several water quality experts, we chose the attribute of probability of impairment of water quality. For "maximizing removal of contaminants of emerging concern from wastewater effluent," which encompasses a wide range of different chemical compounds, we chose the proxy attribute of mass loading of the antibiotic sulfamethoxazole because it was well-characterized in the literature (Jasper et al., 2014a; Jasper and Sedlak, 2013; Radjenović et al., 2008; Batt et al., 2007). We expressed attributes in continuous scales only when we deemed no other attribute to be appropriate. One example was the objective of ease of adaptation which ranged from $0 \%$ (impossible to adapt to changing conditions) to $100 \%$ (very easy and cheap to adapt to changing conditions).

\subsection{Development of management options}

Potential options to manage nutrients were derived from stakeholder interviews, technical documents (e.g., permits, see San Francisco Bay Regional Water Quality Control Board, 2014), and informed by our own understanding of management approaches (see below). The latter included 'Do nothing' to provide a baseline for comparison, as well as urine source separation and treatment as an approach unfamiliar to the local decision-makers but having been considered a viable option in Europe (Lienert and Larsen, 2007). A brief description of each management 
Accepted manuscript: Harris-Lovett, S., Lienert, J., Sedlak, D. L. (2019) A mixed-methods approach to strategic planning for multi-benefit regional water infrastructure. Journal of Environmental Management 233: 218-237.

https://doi.org/10.1016/i.jenvman.2018.11.112.

option is shown in Table 1 (detailed descriptions see Supplemental Information, Table S1). The nitrogen loading reductions below 2017 levels were calculated based on model assumptions (detailed in Supplemental Information, Text S1). 
Accepted manuscript: Harris-Lovett, S., Lienert, J., Sedlak, D. L. (2019) A mixed-methods approach to strategic planning for multi-benefit regional water infrastructure. Journal of Environmental Management 233: 218-237. https://doi.org/10.1016/i.jenvman.2018.11.112.

Table 1. Nitrogen management options considered in the multi-criteria decision analysis. (Photo credits: Wastewater treatment-- By Hasan Zulic/ panoramio/CC BY 3.0/Wikimedia Commons; Wetlands - By US Fish and Wildlife Service/Wikimedia Commons; Recycling - CC-BY-SA3.0/Wikimedia Commons; Roediger NoMix Toilet (urineseparating toilet) - By Sustainable Sanitation Alliance Secretariat/ CC BY 2.0/ Wikimedia Commons)

\begin{tabular}{|c|c|c|c|}
\hline \multicolumn{2}{|l|}{ Management option } & Description & $\begin{array}{l}\text { Nitrogen } \\
\text { loading } \\
\text { reduction } \\
\text { below } 2017 \\
\text { levels }\end{array}$ \\
\hline Do nothing & & No additional action. & 0 \\
\hline \multirow[t]{2}{*}{ Constructed wetlands } & $\begin{array}{l}\text { Horizontal levee } \\
\text { wetlands }\end{array}$ & $\begin{array}{l}\text { Vegetated wetland levees are } \\
\text { built to the maximum possible } \\
\text { extent given spatial constraints. }\end{array}$ & $53 \%$ \\
\hline & $\begin{array}{l}\text { Shallow open-water } \\
\text { wetlands }\end{array}$ & $\begin{array}{l}\text { Open-water wetlands are built to } \\
\text { reduce nitrate loads by } 90 \% \text { at } \\
\text { each wastewater treatment plant } \\
\text { if possible, given spatial } \\
\text { constraints. }\end{array}$ & $65 \%$ \\
\hline \multirow[t]{2}{*}{ Wastewater recycling } & $\begin{array}{l}\text { Increase recycling for } \\
\text { irrigation }\end{array}$ & $\begin{array}{l}\text { Maximize wastewater recycling } \\
\text { for irrigation (without additional } \\
\text { treatment for nutrient removal). }\end{array}$ & $28 \%$ \\
\hline & $\begin{array}{l}\text { Increase recycling for } \\
\text { potable reuse }\end{array}$ & $\begin{array}{l}\text { Maximize recycling of } \\
\text { wastewater for potable reuse, } \\
\text { with a "brine line" to the ocean, } \\
\text { thus diverting nutrients from the } \\
\text { Bay. }\end{array}$ & $26 \%$ \\
\hline \multirow[t]{2}{*}{$\begin{array}{l}\text { Urine source- } \\
\text { separation and } \\
\text { treatment }\end{array}$} & $\begin{array}{l}\text { Install urine source- } \\
\text { separating toilets-early } \\
\text { adopters }\end{array}$ & $\begin{array}{l}\text { Deploy urine-separating toilets } \\
\text { in all new housing and for some } \\
\text { early adopters to divert and treat } \\
\text { urine in decentralized facilities. }\end{array}$ & $1 \%$ \\
\hline & $\begin{array}{l}\text { Install urine source- } \\
\text { separating toilets- with } \\
\text { incentives }\end{array}$ & $\begin{array}{l}\text { Deploy urine-separating toilets } \\
\text { in new housing to divert and } \\
\text { treat urine in decentralized } \\
\text { facilities, with financial } \\
\text { incentives to encourage } 30 \% \\
\text { adoption in existing housing. }\end{array}$ & $14 \%$ \\
\hline \multirow{3}{*}{$\begin{array}{l}\text { Wastewater treatment } \\
\text { plant upgrades (as per } \\
\text { HDR report } \\
\text { specifications) }\end{array}$} & Optimization & $\begin{array}{l}\text { Optimize existing wastewater } \\
\text { treatment processes for total } \\
\text { nitrogen removal. }\end{array}$ & $10 \%$ \\
\hline & Level 2 upgrades & $\begin{array}{l}\text { Upgrades to achieve }<15 \mathrm{mg} \\
\text { TN/L. }\end{array}$ & $55 \%$ \\
\hline & Level 3 upgrades & $\begin{array}{l}\text { Upgrades to achieve }<6 \mathrm{mg} \\
\text { TN/L. }\end{array}$ & $82 \%$ \\
\hline
\end{tabular}


Accepted manuscript: Harris-Lovett, S., Lienert, J., Sedlak, D. L. (2019) A mixed-methods approach to strategic planning for multi-benefit regional water infrastructure. Journal of Environmental Management 233: 218-237. https://doi.org/10.1016/i.jenvman.2018.11.112.

We applied each option to the entire case study region to assess the extent to which it could meet different objectives. However, it is important to note that this approach is not realistic; decisions about technology adoption are much more likely made at a local scale to fit specific community needs related to existing infrastructure, local geography and institutional constraints. The MCDA results for each of the management option should be considered instructive and illustrative but not prescriptive.

Most management options were developed with input from stakeholders in initial interviews. However, the following three management options were added after follow-up interviews with stakeholders to assess how different permutations of the original options affected final rankings:

1.) Constructed open-water wetlands were added as a comparison with sub-surface flow "horizontal levee" wetlands, with different assumptions about land availability, wetland sizing, costs, habitat creation, resilience to sea level rise, and nutrient removal.

2.) Urine source separation initially focused on "early adopters" of the technology. A second option was added with financial incentives for adoption of urine sourceseparation technology, which would achieve greater levels of nutrient removal and would increase reliability of this option.

3.) Potable water recycling with a line for discharging reverse-osmosis concentrate to the ocean was added to address stakeholders' interest in potable water reuse as a water supply option while still reducing the loading of nutrients to the Bay.

Each option was developed by considering the maximum reasonable extent to which it could be applied in the region, based on high-end estimates obtained in planning documents, scientific literature, and from conversations with stakeholders. As a result, each option represents different levels of nutrient removal and different degrees of fulfillment of each objective. All assumptions and detailed parameters of each management option modeled in the MCDA are included in the Supplemental Information, Text S1.

\subsection{Future uncertainty}

To assess the effect of uncertainty in future conditions on technological options for nutrient management, we considered several key factors in the year 2050. We chose 2050 because most wastewater infrastructure is designed to last at least 30-years (Dominguez and Gujer, 2006).

During interviews, stakeholders were asked to list future conditions in 2050 that would likely affect their choice of nutrient management options ("critical uncertainties"). By definition, these were outside of the control of water managers but could profoundly impact the choices of interviewees (Wilkinson and Kupers, 2014). We distilled this information into factors that would most likely influence MCDA results (Mahmoud et al., 2009): population growth, effects of climate change, and the Bay's ecological resilience with respect to nutrient loading. The latter would affect "good water quality" for all treatment options. Changing population size could affect nutrient loading (and hence water quality), loading of contaminants of emerging concern, and sizing of treatment options (which would indirectly affect greenhouse gas emissions and cost). Climate change-related impacts (e.g., magnitude of sea level rise) could affect resilience of treatment options to sea level rise.

Two of these critical uncertainties (i.e., nutrient loading affected by population change and the Bay's ecological resilience to nutrients) were used to develop a matrix of possibilities 
with which to inform the development of future scenarios (Scott et al., 2012; Wright and Goodwin, 2009) (Figure 2). The effect of climate change on wastewater infrastructure located at or near sea level was used to amplify the Worst- and Best-case scenarios developed in the matrix. Population change assumptions were made by extrapolating the most rapid rates of growth and decline in the Bay Area in the past 30 years (Association of Bay Area Governments, 2016) out to 2020. Effects of sea level rise were modeled by assuming a $10 \%$ decrease in the score for the objective "resilience to sea level rise" for each level of increase in effects of sea level rise (on a scale from 0 to 5 ).

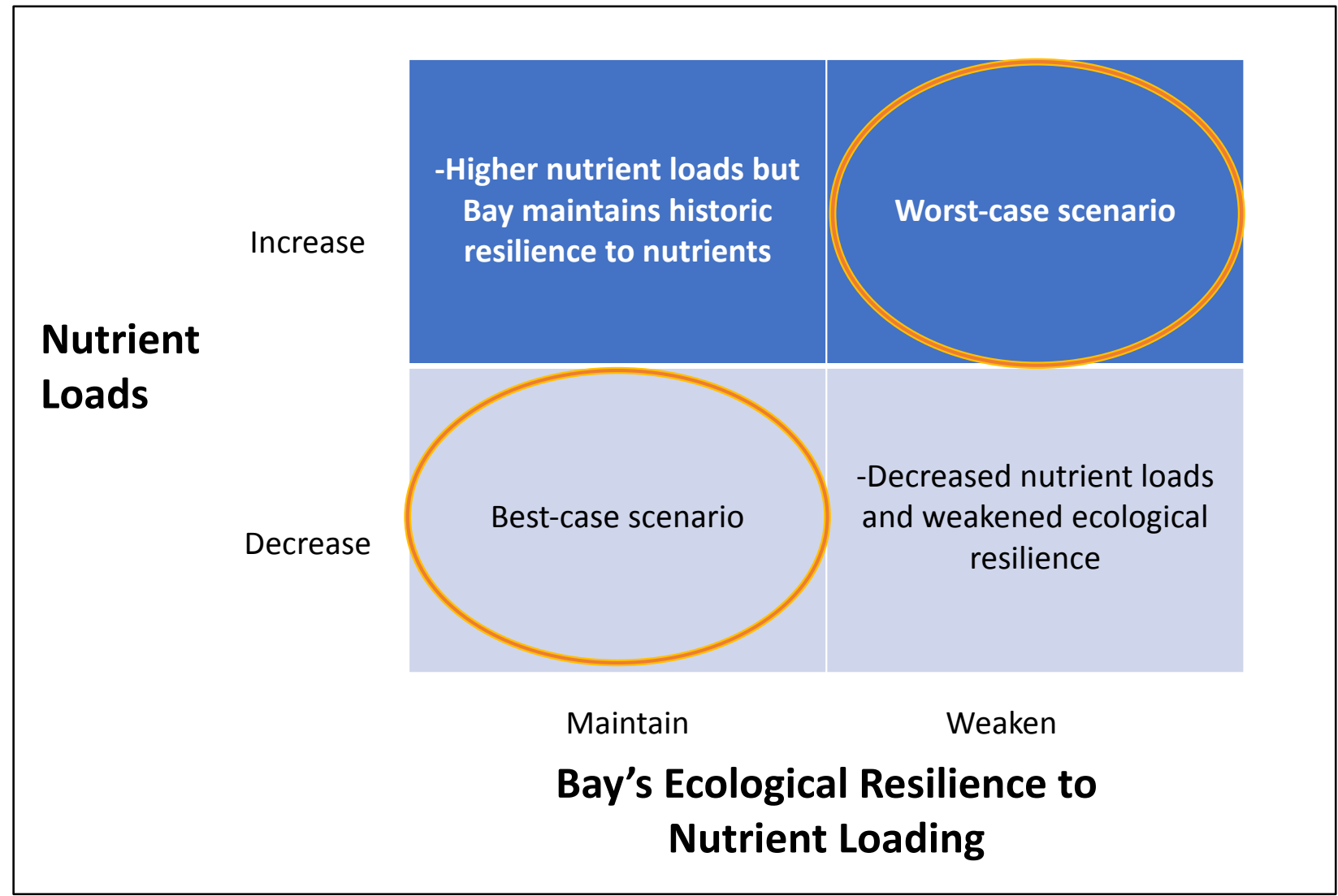

Figure 2. Two key uncertainties, nutrient loads due to population increase and the Bay's ecological resilience to nutrient loading, were used to inform future scenarios for the year 2050.

Our scenarios identify extreme futures by placing positive elements for nutrient control in one scenario and negatives in another (Schoemaker, 1995):

- Worst-case scenario for nutrient impairment. In this scenario, the Bay's ecosystem is much more sensitive to nutrient loading due to system attributes like decreased water column turbidity and increased periods of stratification. Nutrient loading to the Bay increases by $60 \%$ due to rapid population growth between 2017 and 2050. Climate change strongly affects the performance of existing wastewater treatment plants.

- Best-case scenario: less pressure for nutrient control. In this scenario, the Bay retains a strong resilience to nutrient pollution. Nutrient loading to the Bay 
Accepted manuscript: Harris-Lovett, S., Lienert, J., Sedlak, D. L. (2019) A mixed-methods approach to strategic planning for multi-benefit regional water infrastructure. Journal of Environmental Management 233: 218-237. https://doi.org/10.1016/i.jenvman.2018.11.112.

decreases by 13\% due to population decline between 2017 and 2050. Sea level rise does not affect existing wastewater treatment systems.

The "status quo" scenario assumes 33\% population growth by 2050 (roughly $1 \%$ per year; Association of Bay Area Governments and the Metropolitan Transportation Commission, 2017), no effects of climate change on wastewater treatment, and increased ecological sensitivity to nutrient loading. Additionally, we designed the model so that attribute values could be calculated for any level of population size change, five levels of climate change effects between these two extremes, and with or without increased ecological sensitivity to nutrient loading (see associated R-Markdown document, R code for SI and sharing.Rmd and Supplemental Information, Text S2).

The model was run in the open-source software $\mathrm{R}$ (R Core Team, 2013), primarily using the package 'utility' for the MCDA, as well as other packages for analysis and presentation of data ('fitdistrplus', 'truncnorm', 'RColorBrewer', and 'plyr') (Delignette-Muller and Dutang, 2015; Neuwirth, 2014; Reichert et al., 2013; Trautmann et al., 2014; Wickham, 2011). Opensource software was deliberately chosen to allow stakeholders and other researchers to conduct the MCDA under a range of future conditions that are most interesting to them.

The simulations of uncertainty included in the MCDA were based on 1,000 model runs for ease of computing. Although previous MCDA studies which included analyses of uncertainty used 10,000 model runs (Zheng et al., 2016), comparison of median overall values with 1,000 compared to 10,000 were similar and did not change the ranking order of any alternative under any future scenario.

\subsection{Stakeholder analysis and selection for follow-up interviews}

We conducted follow-up interviews with a subset of the original group to elicit a range of opinions on the relative importance of the multiple objectives for nutrient control infrastructure. MCDA results are heavily dependent on the preferences of decision-makers.Although numerous decision makers exist in this case (many more than the 32 initially interviewed), MCDA results in regional decision settings are useful if they can clarify the broad range of interests at play. Here, the selection of participants was designed to represent the breadth of opinions amongst the stakeholders because initial interviews suggested that even individual stakeholders with outlier opinions could have an outsize role in affecting the decision-making process through litigation or negative media attention. To sample these differences of opinion, we performed a cluster analysis of the 32 initially interviewed stakeholders (Mardle et al., 2004; Zahir, 1999). We categorized each response based on their stated goals for nutrient management (presence/absence of each objective in stakeholders' answers to questions about goals for nutrient management).

Our methodology was derived from statistical methods in community ecology. We chose cluster analysis because it well serves our purpose to cluster similar observed characteristics within a larger group (Borcard et al., 2011; McCune and Grace, 2002). We used the software 'R' with packages 'vegan', 'cluster', 'indicspecies' and 'permute' (Oksanen et al., 2017; Gavin Simpson, 2016; Maechler et al., 2016; R Core Team, 2013; Dufrene and Legendre, 1997). To form the clusters, we excluded mentions of the objective "good water quality", because it was clear from the other interview questions that many stakeholders who had not specifically mentioned "good water quality" as a goal implicitly assumed that it was a high priority. We also removed a stakeholder who did not name any objectives for "good nutrient management" due to interview time constraints. 
Accepted manuscript: Harris-Lovett, S., Lienert, J., Sedlak, D. L. (2019) A mixed-methods approach to strategic planning for multi-benefit regional water infrastructure. Journal of Environmental Management 233: 218-237. https://doi.org/10.1016/i.jenvman.2018.11.112.

We used a Bray-Curtis distance measure to form the clusters (which clusters only on shared presence, not shared absences) (Zuur et al., 2007) to group stakeholders by the objectives they considered most important. We used a flexible- $\beta$ linkage, with parameters $\alpha 1=.625, \alpha 2=$ $.625, \beta=-0.25, \gamma=0$ to determine the optimal size and shape of each cluster. We then used a Mantel Test to prune the dendrogram formed in the cluster analysis (Borcard et al., 2011). This resulted in seven clusters, with one to eleven stakeholders. We also conducted a statistical analysis to determine which objectives within each cluster of stakeholders most differentiated them from the other clusters (called an "indicator species analysis" in ecology) (Dufrene and Legendre, 1997). These results are depicted in Table 2.

From each of these clusters, we contacted those stakeholders with the highest relevance to decision-making. This classification was based on the first interview (scale of 1 to 4 , with 1 being most engaged with or most affected by decision-making about nutrient loading). Further selection criteria for follow-up interviews included individuals who had the greatest interest in nutrients in the southern reach of the Bay as determined from initial interviews, and those with diverse professional roles in different agencies. We aimed to include at least one stakeholder from each cluster group in follow-up interviews. Of the 10 stakeholders contacted to participate in follow-up interviews, 9 agreed to participate (stakeholder 30, an engineer at a municipal wastewater utility, was contacted to participate in a second interview but this stakeholder had left their job and was not available).

We randomly assigned numbers 1-9 to the stakeholders who participated in the secondround interviews, and numbers 10-32 for stakeholders who participated in the first-round interviews only.

\subsection{Follow-up interviews for preference elicitation}

In follow-up interviews with nine selected stakeholders, we elicited weights using the Swing method (Schuwirth et al., 2012; Mustajoki et al., 2005). It was chosen because it has been previously used for decision-making about water infrastructure planning (Zheng et al., 2016). Swing is one of the most popular and well-established MCDA weight elicitation methods (see textbooks, e.g. Eisenführ et al., 2010; Belton and Stewart, 2002). To do so, stakeholders first read descriptions of each objective printed on notecards (see Supplemental Information, Text S4 and Text S5) and discussed the objective's importance. They started the weighting exercise by considering a "hypothetical option" where all objectives would be on their worst levels (receiving 0 points). Stakeholders then determined the most important objective to improve from the worst to the best value, assuming that all other objectives would remain on their worst levels; this "best hypothetical option" was assigned 100 points. Stakeholders then chose the next-most important objectives to improve from worst to best values and assigned points (0-100) to each.

Relative point values were then cross-checked for consistency across the objectives hierarchy with stakeholder feedback and adjustments where necessary (Belton and Stewart, 2002). Assigned points were normalized into weights on a scale of 0-1 for each objective for each stakeholder (Belton and Stewart, 2002). Per definition, the sum of weights for each stakeholder equals 1 .

Stakeholders were asked to explain their rationale for assigning points to provide insight into their perspectives on the importance of the objectives and the suitability of the attributes (Marttunen et al., 2015). Attempts to confirm weightings from point allocation results with another common weight elicitation method, the trade-off method (Eisenführ et al., 2010), were almost uniformly rejected by stakeholders (see discussion in Section 4.3.4). 
Accepted manuscript: Harris-Lovett, S., Lienert, J., Sedlak, D. L. (2019) A mixed-methods approach to strategic planning for multi-benefit regional water infrastructure. Journal of Environmental Management 233: 218-237. https://doi.org/10.1016/i.jenvman.2018.11.112.

For the objectives that received the highest weights (and others if time allowed), we elicited the shape of the single-attribute value functions (i.e. whether improvement from the worst to best case fulfillment of the objectives was linear, concave, or convex). We used the bisection elicitation method (Eisenführ et al., 2010). If information was missing, we assumed linear value functions. We also identified if there were any thresholds below which everything was equally bad or above which everything was equally good (Scholten et al., 2015). Interview guidelines for follow-up interviews are included in the Supplemental Information, Figure S1. A more detailed description of methods for preference elicitation is included in Supplemental Information, Text S3.

Second round interviews were conducted in person and took 60 to 120 minutes.

Protocols for follow-up interviews were approved by the Human Subjects Committee (the Institutional Review Board) at the University of California, Berkeley.

\subsection{Prediction of attribute values for each management option}

Predictions of attribute outcomes are uncertain, especially in complex environmental systems (Reichert et al., 2015). To approximate this uncertainty, we used a combination of estimates from the literature, expert assessment, and modeling to determine an uncertainty range for each attribute predictions (Scholten et al., 2013).

Given the estimated uncertainty range and distribution for each attribute value (see Supplemental Information, Table S2), we developed a matrix of 1,000 random potential attribute values for each objective for each option. If less than 3\% of modeled values fell outside the worst-best range (as in the case of a normal distribution with a mean of 98 and a standard deviation of 1 , with a top limit of 100), the mean value was used to replace those values that exceeded the limits of the range so that one extreme would not be over-represented in the model.

After calculation of the attribute values for each option, the option of potable water recycling with a pipeline to the ocean to dispose of reverse-osmosis brine was found to have a value of $\mathrm{CO}_{2}$ emissions two orders of magnitude higher than the "worst" value used in the elicitation process. (This option was added after the second interviews based on stakeholder interest in potable water recycling as a means of nutrient control.) Some MCDA practitioners have suggested that the attribute range can be extended by assuming that stakeholders' preference weights would increase linearly (Eisenführ et al., 2010). However, this assumption is likely invalid in this case given how far outside the initial range this new option lies. Even with the un-adjusted weightings, potable water recycling with a pipeline for brine disposal option scored relatively low for most stakeholders (Supplemental Information, Table S6). Moreover, because the re-adjusted weights within the new range of $\mathrm{CO}_{2}$ values would dramatically increase the weight of $\mathrm{CO}_{2}$ emissions (and thus decrease the overall score of the option), we decided not to include this option in the remainder of the analyses. To include it, either the stakeholders' objective weights for such high potential $\mathrm{CO}_{2}$ emissions would have to be re-elicited, or the option would have to be reconfigured with another means of concentrate disposal (e.g., zeroliquid discharge systems, emerging concentrate treatment technology).

\subsection{Multi-criteria decision analysis}

The MCDA was conducted in R using the 'utility' package (Reichert et al., 2013). The attributes for the objectives (termed 'end-nodes' in the MCDA software) were assumed to be single-attribute continuous parametric functions (for each value of ' $x$ ' there is only one value of ' $y$ '). Overarching objectives (mid- and top-level aggregation nodes) were assumed to be 
Accepted manuscript: Harris-Lovett, S., Lienert, J., Sedlak, D. L. (2019) A mixed-methods approach to strategic planning for multi-benefit regional water infrastructure. Journal of Environmental Management 233: 218-237. https://doi.org/10.1016/i.jenvman.2018.11.112.

aggregations of lower-level nodes and were assumed to convert to overall values using a continuous parametric function (rather than discrete classes).

Two stakeholders required separate objectives hierarchies. For stakeholder 3 (SH3), an objectives hierarchy was built that did not include water quality because the stakeholder refused to consider a probabilistic measure of impairment. Instead, SH3 suggested that impairment should be a "true/false" measure of existing ecological conditions. SH3's objectives hierarchy also did not include habitat because $\mathrm{SH} 3$ refused to choose between personal sentiments and professional sentiments about the importance of habitat regarding nutrient management (SH3 indicated that their personal opinions were at odds with their professional mandates). For stakeholder 7 (SH7), the objectives hierarchy did not include recovery of nutrients from wastewater, because SH7 refused to accept a measure of nutrient recovery that did not include nutrient recovery from solids removed during conventional wastewater treatment. Though SH3 and SH7 are included in the results, it is important to note that their overall rankings of options, while still instructive, are not comparable to those of other stakeholders.

We used a simpler MCDA model to determine results for each stakeholders' individual preferences (additive aggregation, linear value functions, no uncertainty in stakeholder weights) because the aim of our model is to provide structure for discussion within a broader decisionmaking effort, not to definitively provide a solution to a problem (Scholten et al., 2017).

\subsubsection{MCDA aggregation function}

As a baseline case, we assumed additive aggregation of the nodes to determine the overall value of each option. Additive aggregation is commonly employed in MCDA. It implies that high attribute values for one objective completely compensate for low attribute values for another (Eisenführ et al., 2010). However, additive aggregation has been shown to be an inaccurate representation of stakeholder perspectives in some cases (Langhans et al., 2014). Despite this shortcoming, additive aggregation is considered a valid simplification in some MCDA cases because changes in the aggregation method do not necessarily change the ranking of options in the MCDA output (Scholten et al., 2017).

\subsubsection{Marginal value functions}

As an initial baseline case, all value functions were assumed to be linear and no thresholds (strict limits in attribute values) were included. Linear value functions are considered a valid simplifying assumption for many MCDAs (Scholten et al., 2017). We resorted to these because time constraints in interviews prevented us from querying all interviewees about the shape of the marginal value function of attribute fulfillment or thresholds. Additionally, most interviewees who discussed value functions gave vague curvatures rather than discrete midpoint values. The baseline case assumptions and resulting rankings were then tested in a sensitivity analysis (sections 3.5.1 and 3.5.4) (Scholten et al., 2017; Zheng et al., 2016).

\section{Results}

\subsection{Stakeholder analysis}

The selected group of stakeholders included water managers, baylands ecological stewards, scientific researchers and engineers, regulators, urban planners, flood control managers, and advocates for coastal industry or environment at the local, regional, and federal scales (Kunz et al., 2013). The stakeholders represented 76 separate organizations or agencies. Several stakeholders represented more than one organization (e.g., one person served as director 
Accepted manuscript: Harris-Lovett, S., Lienert, J., Sedlak, D. L. (2019) A mixed-methods approach to strategic planning for multi-benefit regional water infrastructure. Journal of Environmental Management 233: 218-237. https://doi.org/10.1016/i.jenvman.2018.11.112.

of an industrial advocacy group and also served on the board of a public wastewater utility). Of the 88 individuals contacted, 32 stakeholders (representing 29 different organizations) participated in an interview.

Stakeholders with the same professional role (i.e. discharger, regulator) and even within the same organization frequently stated different goals for nutrient management, as evidenced by their failure to cluster together (Table 2). They also weighed the importance of objectives differently. In other words, it would be inaccurate to assume that all dischargers or all regulators have the same objectives. Stakeholder weights for each objective are summarized in the Supplemental Information, Figure S2. 
Accepted manuscript: Harris-Lovett, S., Lienert, J., Sedlak, D. L. (2019) A mixed-methods approach to strategic planning for multibenefit regional water infrastructure. Journal of Environmental Management 233: 218-237.

https://doi.org/10.1016/i.jenvman.2018.11.112.

Table 2. Stakeholder clusters based on stated goals for nutrient management. Stakeholders 1-9 (in bold) participated in follow-up interviews. Relevance denotes how strongly a stakeholder was engaged in or affected by decision-making about nutrient loading $(1=$ directly involved in decision-making; 2 = strongly affected by decision-making, or with strong influence over decision-makers; $3=$ slightly affected by decision-making; 4 = interested/concerned with nutrients, but not directly affected by decision-making).

\begin{tabular}{|c|c|c|c|c|}
\hline $\begin{array}{l}\text { Objective } \\
\text { cluster group }\end{array}$ & Cluster group characteristic & Relevance & Stakeholder & Professional role \\
\hline \multirow[t]{6}{*}{1} & \multirow[t]{6}{*}{ Wildlife habitat } & 1 & SH6 & regulator \\
\hline & & 1 & SH12 & regulator \\
\hline & & 2 & SH19 & discharger \\
\hline & & 2 & SH16 & regulator \\
\hline & & 2 & SH18 & researcher, advocate \\
\hline & & 3 & SH25 & steward, researcher \\
\hline \multirow[t]{11}{*}{2} & \multirow[t]{11}{*}{ Low costs and water supply } & 1 & SH8 & advocate \\
\hline & & 1 & SH22 & discharger \\
\hline & & 1 & SH2 & discharger \\
\hline & & 1 & SH9 & regulator \\
\hline & & 1 & SH10 & regulator \\
\hline & & 2 & SH21 & discharger \\
\hline & & 2 & SH23 & engineer \\
\hline & & 3 & $\mathrm{SH} 26$ & water supplier \\
\hline & & 4 & SH17 & advocate \\
\hline & & 4 & $\mathrm{SH} 24$ & researcher \\
\hline & & 4 & SH15 & water supplier \\
\hline \multirow[t]{6}{*}{3} & \multirow{6}{*}{$\begin{array}{l}\text { Need science-based understanding of } \\
\text { nutrient effects on ecosystem }\end{array}$} & 1 & SH1 & advocate \\
\hline & & 1 & SH32 & discharger \\
\hline & & 1 & SH3 & discharger \\
\hline & & 1 & SH4 & regulator \\
\hline & & 1 & SH13 & regulator \\
\hline & & 2 & SH27 & regulator \\
\hline \multirow[t]{2}{*}{4} & \multirow[t]{2}{*}{ Technical reliability } & 2 & SH30 & discharger \\
\hline & & 4 & SH11 & planner \\
\hline \multirow[t]{4}{*}{5} & \multirow[t]{4}{*}{ Collaboration across professional fields } & 1 & SH28 & discharger \\
\hline & & 1 & SH7 & discharger \\
\hline & & 4 & SH31 & $\begin{array}{l}\text { engineer, planner, } \\
\text { regulator }\end{array}$ \\
\hline & & 4 & SH20 & researcher, steward \\
\hline 6 & NA & 4 & SH14 & regulator \\
\hline \multirow[t]{2}{*}{7} & \multirow{2}{*}{$\begin{array}{l}\text { Balance nutrients with other long-term } \\
\text { management goals }\end{array}$} & 3 & SH5 & steward \\
\hline & & 4 & SH29 & $\begin{array}{l}\text { engineer, planner, } \\
\text { regulator }\end{array}$ \\
\hline
\end{tabular}


Several stakeholders mentioned thresholds in their tolerance for low fulfillment of certain objectives. They tended to have thresholds for several objectives. Three respondents said they would not accept any option for nutrient management that was below a certain level for water quality, measured by probability (\%) of deviating from good nutrient-related conditions in the southern reach of the Bay. These levels for water quality were worse than $15 \%$ (wastewater dischargers advocate), 20\% (coastal land steward), and 50\% (regulator). One stakeholder (regulator) would not endorse any nutrient management option that did not protect existing infrastructure from sea level rise. Two stakeholders (coastal land steward, wastewater dischargers advocate) would not accept any option with levels of ease of adaptation below $76 \%$ and $50 \%$, respectively. Three stakeholders (regional regulator, coastal land steward, wastewater dischargers advocate) would not accept any option with levels of reliability below $70 \%, 80 \%$, and $85 \%$, respectively. Effects of these thresholds on the MCDA results are calculated in the sensitivity analysis (section 3.5.1).

\subsection{Objectives for good nutrient management}

The objectives and attributes for good nutrient management in San Francisco Bay (Table 3) indicate stakeholders have a wide variety of goals, some of which are outside the scope of traditional wastewater infrastructure planning (Harris-Lovett et al., 2018). For details and rationale about how each attribute was calculated, see the Supplemental Information, Text S1. 


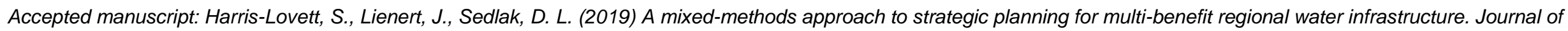
Environmental Management 233: 218-237. https://doi.org/10.1016/j.jenvman.2018.11.112.

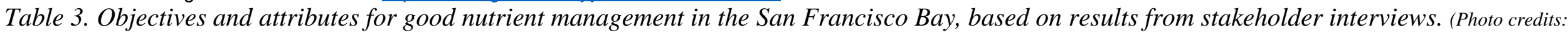
Heron fishing - Chris Harshaw/CC BY-SA 3.0/Wikimedia Commons; Wastewater treatment plant--OpenStax/ CC BY 4.0/Wikimedia Commons; Footprint - from

http://www.greencareers.biz/faq/what-does-it-mean-to-offset-your-carbon-footprint/; Thumbs up - Pratheeps/Wikimedia Commons)

\begin{tabular}{|c|c|c|c|c|}
\hline Goal & Objective & Attribute & Unit & Description \\
\hline $\begin{array}{l}\text { Healthy estuarine } \\
\text { ecosystem } \\
+3\end{array}$ & Good water quality & $\begin{array}{l}\text { Probability of deviating from } \\
\text { good nutrient-related water } \\
\text { conditions }\end{array}$ & $\%$ & $\begin{array}{l}\text { Nutrient over-enrichment could result in eutrophication and impairment of } \\
\text { beneficial uses (Sutula and Senn, 2015). Expert estimates of the attribute were } \\
\text { made based on percent nitrogen load change from current levels. }\end{array}$ \\
\hline \multirow{3}{*}{$\begin{array}{l}\text { Maximize treatment } \\
\text { and beneficial uses } \\
\text { of wastewater }\end{array}$} & Increase water supply & Usable water produced & $\begin{array}{l}\text { MGD (million } \\
\text { gallons /day) }\end{array}$ & $\begin{array}{l}\text { Attribute estimates were derived from utility planning documents (e.g., San } \\
\text { Francisco Public Utilities Commission, 2016). }\end{array}$ \\
\hline & $\begin{array}{l}\text { Increase resource } \\
\text { recovery }\end{array}$ & $\begin{array}{l}\text { Recovered nitrogen }(\mathrm{N}) \text { from } \\
\text { effluent that can be used as } \\
\text { fertilizer }\end{array}$ & Kg N/Year & $\begin{array}{l}\text { Attribute estimates for nitrogen recovery from urine-source separation were } \\
\text { derived from academic literature (e.g., Tarpeh et al., 2017). Recycling for } \\
\text { irrigation was assumed to utilize all nutrients (Vazquez-Montiel et al., 1996). }\end{array}$ \\
\hline & $\begin{array}{l}\text { Maximize removal of } \\
\text { unregulated } \\
\text { contaminants (CEC) }\end{array}$ & $\begin{array}{l}\text { Total sulfamethoxazole } \\
\text { (SMX) loading in the } \\
\text { southern reach of the Bay }\end{array}$ & Kg SMX /year & $\begin{array}{l}\text { Sulfamethoxazole was used as a proxy for CECs because its removal in } \\
\text { wastewater treatment is relatively well characterized (Batt et al., 2007; Jasper } \\
\text { et al., 2014a; Jasper and Sedlak, 2013; Radjenović et al., 2008). }\end{array}$ \\
\hline \multirow[t]{3}{*}{$\begin{array}{l}\text { Promote inter- } \\
\text { generational equity }\end{array}$} & $\begin{array}{l}\text { Ease of adaptation as } \\
\text { conditions change }\end{array}$ & $\begin{array}{l}\text { Percent ease of adaptation } \\
\text { (considers sunk costs, time, } \\
\text { physical potential) }\end{array}$ & $\%$ & $\begin{array}{l}\text { Wastewater infrastructure that can be quickly and cheaply adapted to deal with } \\
\text { changing influent flows and/or concentrations and to achieve more stringent } \\
\text { regulatory standards is desirable. Classification: } 0-50 \% \text { : Impossible or hard to } \\
\text { adapt; } 51-75 \% \text { : Moderately adaptable; } 76-100 \% \text { : Easy to adapt. }\end{array}$ \\
\hline & $\begin{array}{l}\text { Resilience to sea level } \\
\text { rise (SLR) }\end{array}$ & $\begin{array}{l}\text { Extent to which technology } \\
\text { is vulnerable to SLR and } \\
\text { storm surges }\end{array}$ & $\begin{array}{l}\text { Constructed } \\
\text { scale }\end{array}$ & $\begin{array}{l}\text { SLR poses a threat to many of the Bay Area's wastewater treatment plants } \\
\text { (Heberger et al., 2009). Scale from -10 to 10; with 10: Protects existing assets } \\
\text { from SLR; 0: Unaffected by SLR; -10: Highly vulnerable to SLR. }\end{array}$ \\
\hline & $\begin{array}{l}\text { Low greenhouse gas } \\
\text { (GHG) emissions }\end{array}$ & $\begin{array}{l}\text { Lifecycle GHG emissions of } \\
\text { wastewater treatment }\end{array}$ & $\mathrm{CO}_{2}$ eq. /year & $\begin{array}{l}\text { Attribute estimates from literature on emissions of wastewater treatment } \\
\text { (Stokes and Horvath, 2009) and nitrogen removal (Corominas et al., 2013). }\end{array}$ \\
\hline \multirow[t]{3}{*}{ Good social support } & $\begin{array}{l}\text { Maximize public's } \\
\text { ease of use }\end{array}$ & Percent ease of use & $\%$ & $\begin{array}{l}\text { Some technologies could require involvement or behavior change by end users } \\
\text { (e.g., urine source-separating toilets requiring men to sit when urinating). } \\
\text { Classification: } 0-60 \% \text { : Requires behavior change from users; } 61-80 \% \text { : Mental } \\
\text { shift but no behavior change required; } 80-100 \% \text { : Easy to use. }\end{array}$ \\
\hline & $\begin{array}{l}\text { Increase shoreline } \\
\text { access }\end{array}$ & $\begin{array}{l}\text { Additional access points } \\
\text { (above } 2017 \text { levels) }\end{array}$ & Number & $\begin{array}{l}\text { Access to aesthetically pleasing places along the Bay shore for recreation is } \\
\text { desirable. }\end{array}$ \\
\hline & $\begin{array}{l}\text { Maximize ease of } \\
\text { permitting }\end{array}$ & Percent ease of permitting & $\%$ & $\begin{array}{l}\text { Classification: } 0-60 \% \text { : Permitting requires much additional staff time and/or } \\
\text { legislative change; } 61-80 \% \text { : Permitting requires some additional staff time; } 81 \text { - } \\
100 \% \text { : Easy to permit. }\end{array}$ \\
\hline Minimize costs & Technical reliability & $\begin{array}{l}\text { Percent of time technology } \\
\text { operates as intended }\end{array}$ & $\%$ & Derived from expert estimates. \\
\hline
\end{tabular}


Confidential manuscript submitted to Journal of Environmental Management; Harris-Lovett, Lienert, Sedlak

\subsection{Prediction of attribute values}

Mean attribute values for the Status Quo scenario are shown in Table 4 as an example. Attribute values for the Worst- and Best-case scenario, and status quo population growth without increased sensitivity to nutrient loading are included in the Supplemental Information, Tables S3-S5. 
Confidential manuscript submitted to Journal of Environmental Management; Harris-Lovett, Lienert, Sedlak

Table 4. Mean attribute values (rows; see Tab. 3) for each management option (columns; see Tab. 1) in 2050 assuming the Status Quo scenario: $33 \%$ population growth, no effects of climate change on wastewater operations, and increased ecological sensitivity to nutrient loading.

\begin{tabular}{|c|c|c|c|c|c|c|c|c|c|c|}
\hline \multirow[t]{3}{*}{ Objectives - Attributes [units]: best-worst range } & \multicolumn{10}{|c|}{ Management options } \\
\hline & \multirow[b]{2}{*}{ 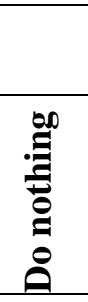 } & \multicolumn{2}{|c|}{$\begin{array}{l}\text { Constructed } \\
\text { wetlands }\end{array}$} & \multicolumn{2}{|c|}{$\begin{array}{c}\text { Wastewater } \\
\text { recycling }\end{array}$} & \multicolumn{2}{|c|}{$\begin{array}{c}\text { Urine separation } \\
\text { and treatment }\end{array}$} & \multicolumn{3}{|c|}{$\begin{array}{l}\text { Wastewater treatment } \\
\text { plant upgrades }\end{array}$} \\
\hline & & 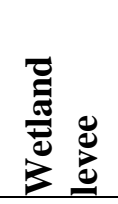 & 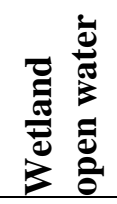 & 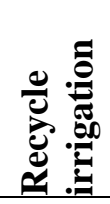 & 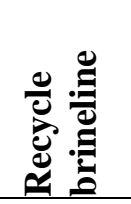 & 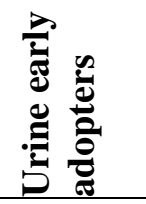 & : & 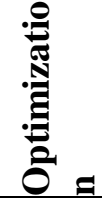 & 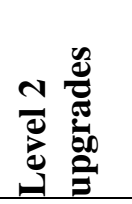 & 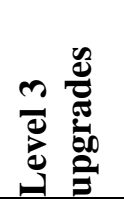 \\
\hline Good water quality -- Deviation probability from good quality [\%]: 5-95 & 74 & 40 & 32 & 59 & 60 & 68 & 57 & 67 & 35 & 17 \\
\hline $\begin{array}{l}\text { Good wildlife habitat -- Additional wetland habitat [square hectares]: 0- } \\
5200\end{array}$ & 0 & 4,200 & 790 & 0 & 0 & 0 & 0 & 0 & 0 & 0 \\
\hline Increase water supply -- Usable water produced [MGD]: 154-22 & 22 & 22 & 22 & 120 & 100 & 22 & 22 & 22 & 22 & 22 \\
\hline $\begin{array}{l}\text { Increase resource recovery -- Nitrogen }(\mathrm{N}) \text { recovery [Mkg N/year]: 8,500- } \\
0\end{array}$ & 0 & 0 & 0 & 3,300 & 0 & 1,800 & 4,300 & 0 & 0 & 0 \\
\hline $\begin{array}{l}\text { Maximize removal of contaminants of emerging concern -- Total } \\
\text { sulfamethoxazole loading [kg SMX /year]: 31-137 }\end{array}$ & 85 & 56 & 70 & 60 & 64 & 56 & 47 & 86 & 78 & 79 \\
\hline Ease of adaptation -- Percent ease of adaptation [\%]: 100-0 & 100 & 53 & 42 & 45 & 45 & 85 & 55 & 75 & 52 & 10 \\
\hline $\begin{array}{l}\text { Resilience to sea level rise -- Scale [-10 (highly vulnerable) to } 10 \text { (protects } \\
\text { infrastructure)]:- } 10 \text { to } 10\end{array}$ & -5 & 8 & 5 & -3 & -5 & 0 & 0 & -5 & -5 & -5 \\
\hline $\begin{array}{l}\text { Low greenhouse gas emissions -- Lifecycle emissions for wastewater } \\
\text { treatment }\left[\mathrm{Kkg} \mathrm{CO}_{2} \text { eq. /year]: } 200-900\right.\end{array}$ & 290 & 350 & 310 & 430 & 70,000 & 290 & 290 & 290 & 380 & 660 \\
\hline Maximize public's ease of use -- Percent public ease of use [\%]: 100-0 & 100 & 100 & 100 & 100 & 55 & 33 & 35 & 100 & 100 & 100 \\
\hline Increase shoreline access -- Number of additional access points [\#]: 17-0 & 0 & 8.5 & 8.5 & 0 & 0 & 0 & 0 & 0 & 0 & 0 \\
\hline Maximize ease of permitting -- Percent ease of permitting [\%]: 100-0 & 100 & 33 & 31 & 80 & 45 & 45 & 40 & 90 & 90 & 90 \\
\hline $\begin{array}{l}\text { Technical reliability -- Percent of time nutrient technology operates as } \\
\text { intended [\%]: } 98-50\end{array}$ & 100 & 77 & 77 & 91 & 98 & 66 & 76 & 98 & 98 & 98 \\
\hline $\begin{array}{l}\text { Minimize initial capital investment and O\&M costs -- Net present value } \\
\text { over } 30 \text {-year span }[\$ 1,000,000]: 0-8,000\end{array}$ & 0 & 2,700 & 1,200 & 2,200 & 370 & 400 & 5,300 & 170 & 2,500 & 3,200 \\
\hline
\end{tabular}


Confidential manuscript submitted to Journal of Environmental Management; Harris-Lovett, Lienert, Sedlak

\subsection{Multi-criteria decision analysis}

The MCDA produced an overall value for each management option and stakeholder based on the attribute values and the stakeholder weights for each objective (Figure 3). There was no option that scored highest for all stakeholders. However, increasing wastewater recycling for irrigation (in dark green) and building horizontal wetland levees (in dark blue) were among the top three options for most stakeholders under all future scenarios (Fig. S3 for other future scenarios). Conversely, both urine source-separation options (in pink and red) and Level 3 upgrades of wastewater treatment plants (in purple) were the lowest ranked options for most stakeholders under all future scenarios.

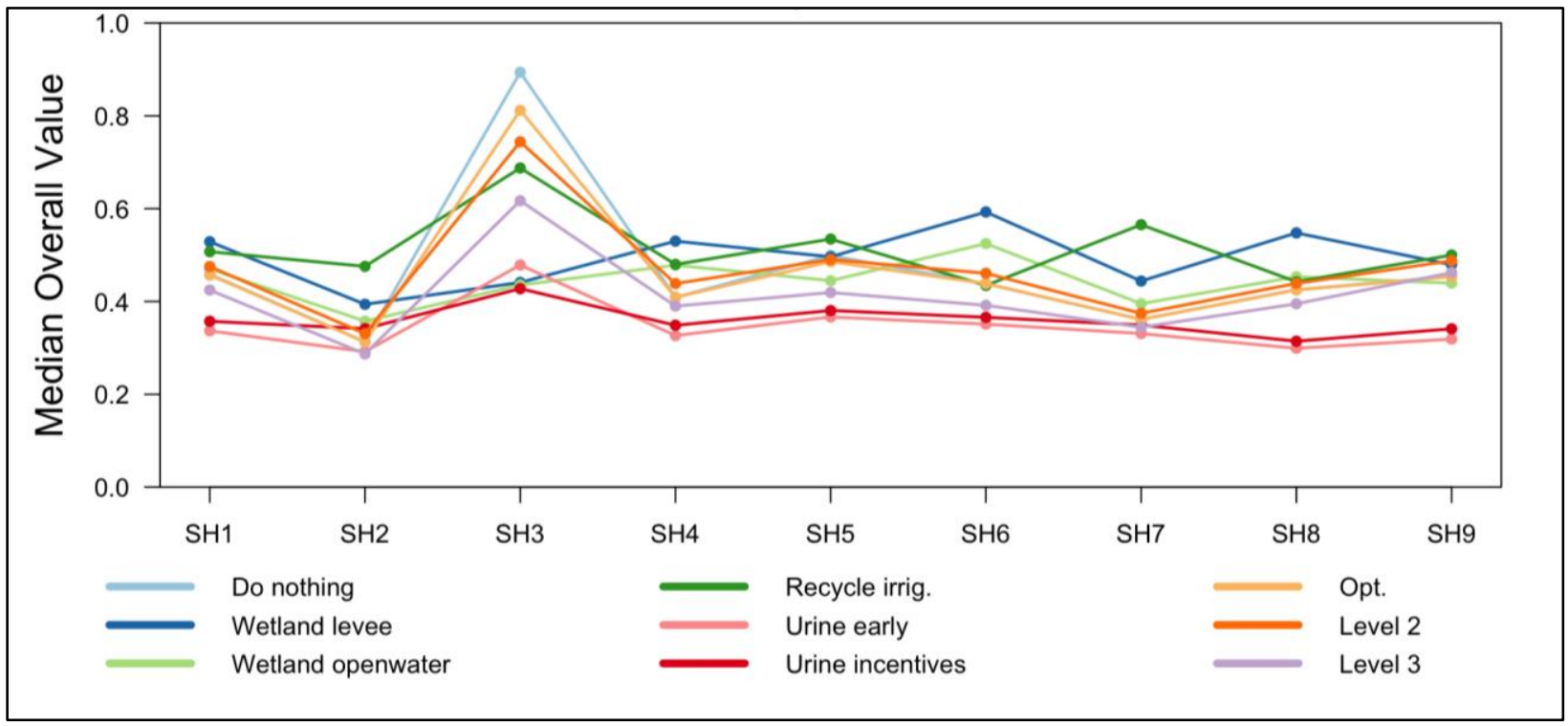

Figure 3. Median overall value as result of the MCDA for each management option (colored lines; see Tab. 1) for each of nine stakeholders (SH; on x-axis) in the Status quo scenario. A value of 1 indicates that all objectives are fully achieved, a value of 0 that none of the objectives are achieved.

In the Best- and Worst-case scenarios, the median overall scores were strikingly similar to those of the Status quo, but the overall values were shifted slightly higher for the Best-case scenario and slightly lower for the Worst-case scenario (shown in Supplemental Information, Figure S3).

Including uncertainty about attribute predictions into calculations of overall value for each option (Figure 4) indicated that uncertainties in attribute predictions made more difference to overall value than future conditions for the less-established management options like the wetland options (horizontal levee and open water), recycling for irrigation, and the urine sourceseparation. In these cases, the values for each future scenario were very close (solid colored lines), while the values including the uncertainty of attribute predictions were far apart (dashed lines; see top rows (middle and right) and middle row in Figure 4). Future conditions were the main cause of uncertainty in overall value for options in which the management option performance was well established, like optimization, Level 2, and Level 3 upgrades of wastewater treatment plants. In these cases, the dashed lines (uncertainty of attribute predictions) 
Confidential manuscript submitted to Journal of Environmental Management; Harris-Lovett, Lienert, Sedlak

were close to the respective solid lines (median of scenarios), while the values for the scenarios (colors) differed relatively strongly (bottom row in Figure 4).

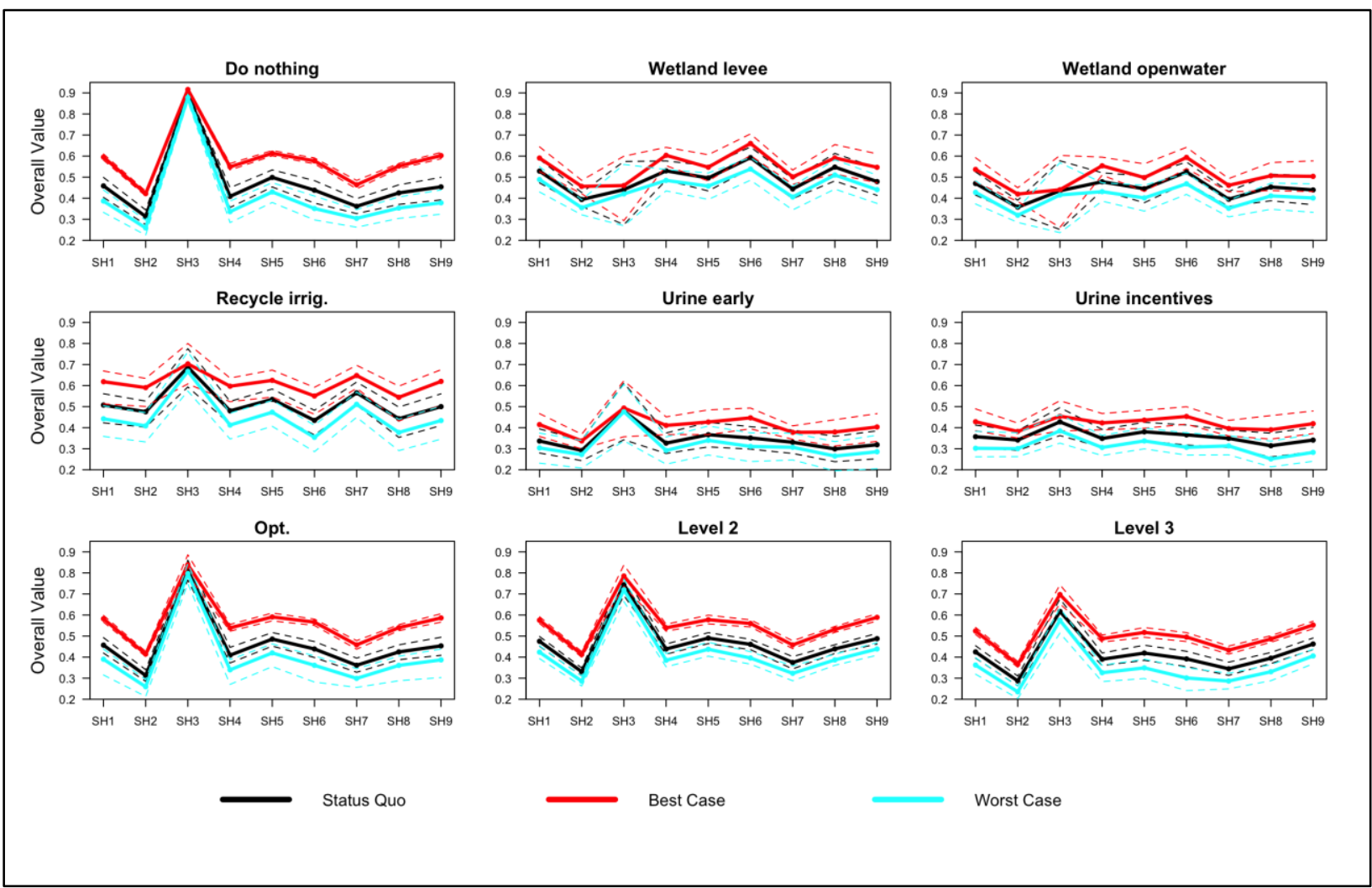

Figure 4. Overall values for each management option (see Tab. 1) for each of nine stakeholders (SH; on X-axis) under three future scenarios (lines: status quo, best, and worst case). Solid lines denote median overall values in each scenario, dashed lines represent $5 \%$ and $95 \%$ quartile values.

Overall scores for each option for each stakeholder were converted to ranks (from 1-9, with 1 being the top-ranked option compared to the others). In this analysis, less well-established options like constructed wetlands (horizontal levees) and increased recycling for irrigation were likely to be in the top three ranked options for 8 of the 9 stakeholders in the Status quo scenario (Figure 5). In many cases, the rank of each option was affected by uncertainty in attribute prediction, often spanning 4 or more ranks. 
Confidential manuscript submitted to Journal of Environmental Management; Harris-Lovett, Lienert, Sedlak

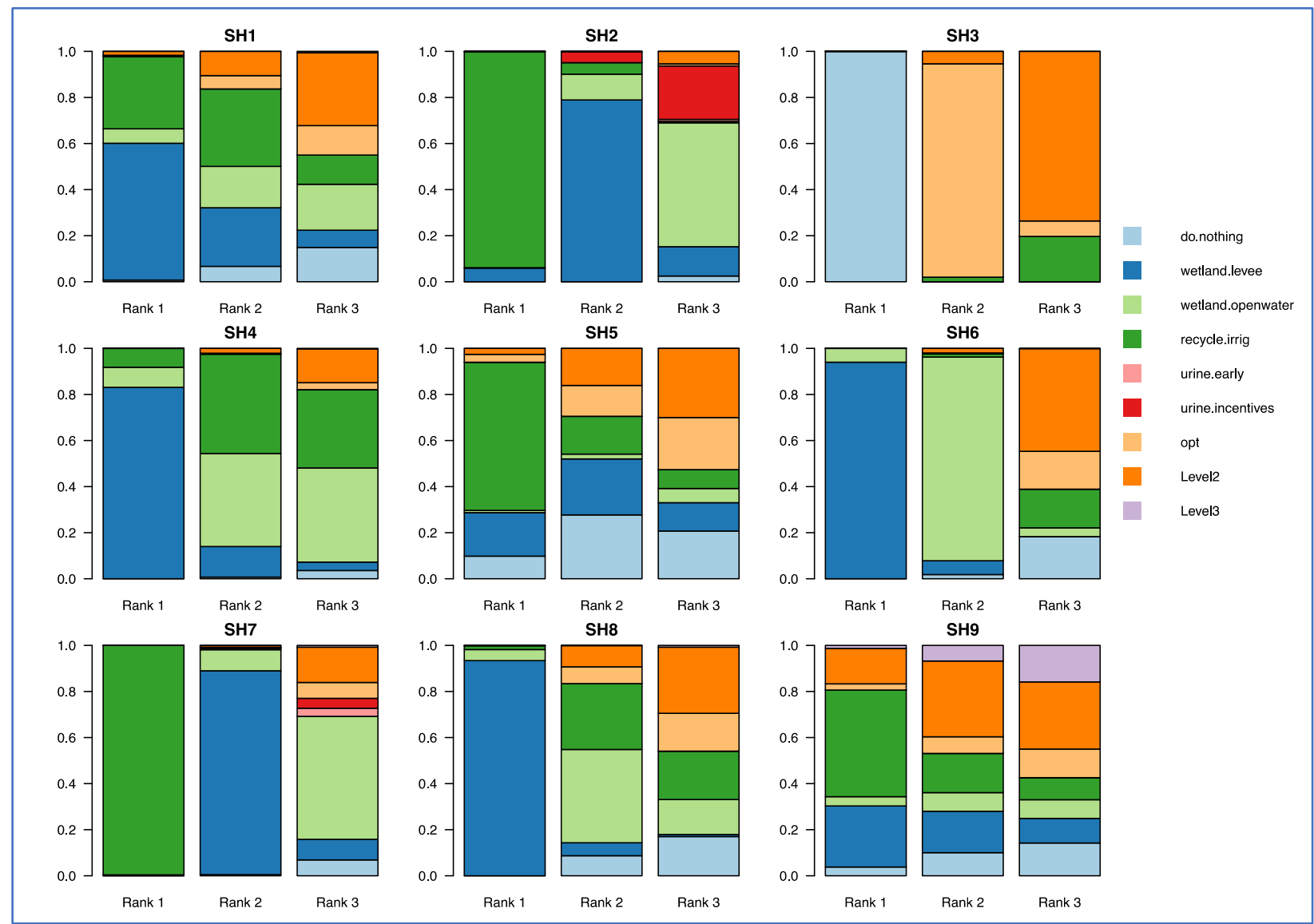

Figure 5. The probability of the top three ranked options for each of nine stakeholders (SH) given uncertainty in attribute predictions, Status quo scenario. Color coding options see legend and Table 1.

The probability of the top three ranked options for each stakeholder was virtually unchanged in the Worst-case scenario (Supplemental Information, Figure S4). For the Best-case scenario, the 'Do nothing' option moved into the top three or became far better for nearly all stakeholders, and optimization improved for many stakeholders as well (Supplemental Information, Figure S5). In other words, traditional responses fared better under the best-case scenario. In general, Level 3 upgrades of treatment plants and the urine-source separation options ranked lower than the other options for nearly all stakeholders under a range of future conditions (Supplemental Information, Figures S6-S8).

A closer look at the contribution of each objective to overall values for an individual stakeholder reveals that the benefits other than water quality of some of the less-traditional nutrient management options helped boost their overall value above that of conventional wastewater treatment plant upgrades (Figure 6). For example, for stakeholder 4 (SH4), the three best-performing options (two wetland options, recycling wastewater for irrigation) achieved comparatively high values on nearly all objectives. Notably, the wetland alternatives achieved good values for the added benefits of shoreline access (purple band in Figure 6) and wetland habitat (dark blue), whereas all other options did not contribute to meeting these two objectives at all. The option of recycling wastewater for irrigation was the only one to fulfill the objective of increasing water supply (light green). For Level 3 upgrades of treatment plants, scoring highly 
Confidential manuscript submitted to Journal of Environmental Management; Harris-Lovett, Lienert, Sedlak

in water quality (light blue), permitting (yellow), and reliability (brown) did not compensate for low scores for the $\mathrm{CO}_{2}$ emissions (orange) and ease of adaptation (red) objectives and a lack of co-benefits like water supply or wetland habitat for SH4.

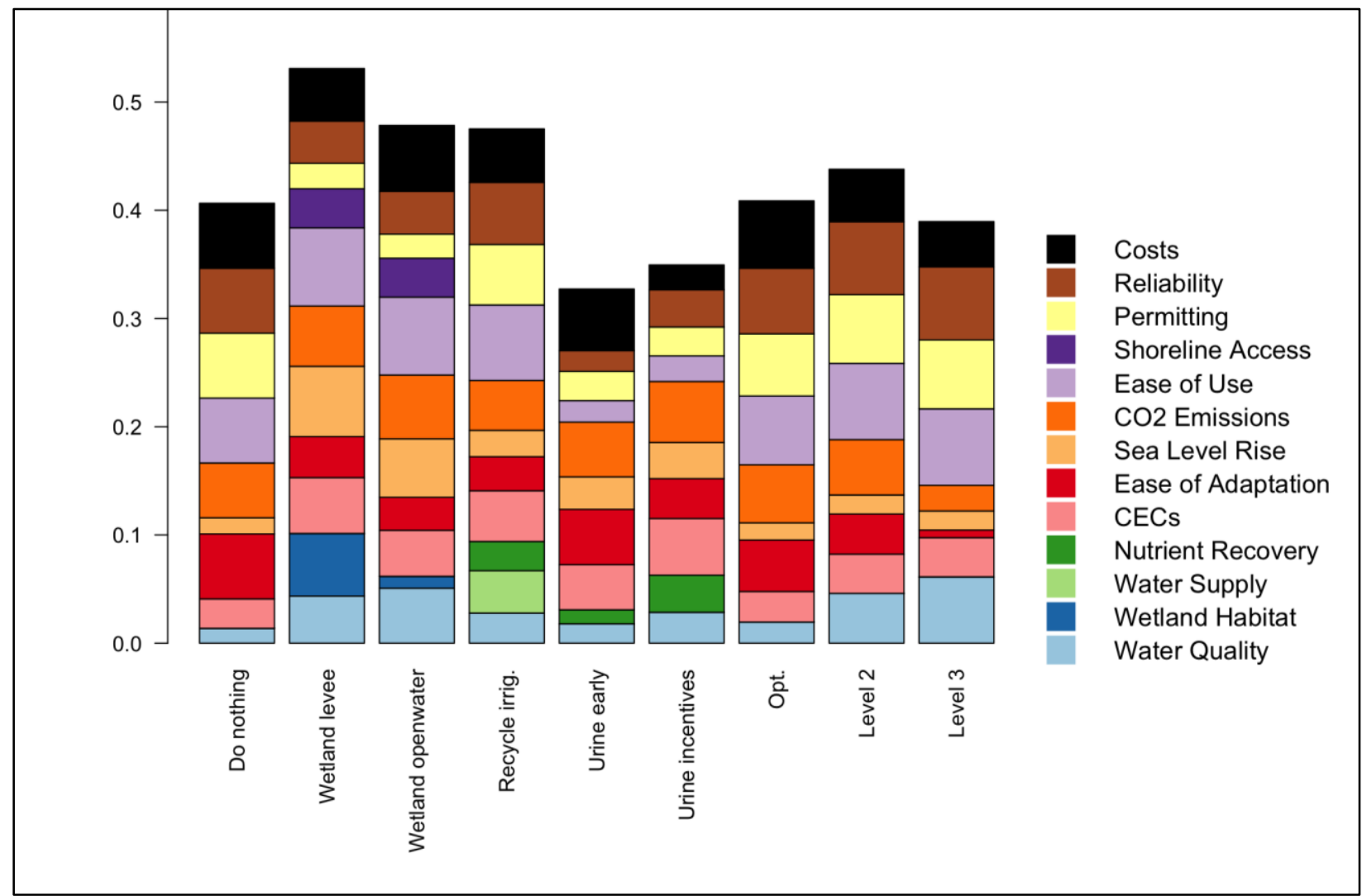

Figure 6. Median overall value (y-axis) of each option (x-axis; see Tab. 1), broken down by objectives (in color; see Tab. 4) for stakeholder SH4 in the Status quo scenario. This figure illustrates for one stakeholder, how strongly each objective contributes to the overall value for each option. Narrow bars: low contribution to overall value; broad bars: large contribution.

\subsection{Comparison of MCDA with cost efficiency}

Several stakeholders expressed that they would normally assess the value of a nutrient management option through a 'cost-efficiency' measure (mass of nutrients removed from wastewater / dollar). The results for each option (Figure 7) assumed the mean cost (total net present value over 30-year technology lifespan) in the uncertainty distributions and the total nitrogen removal (kg of total $\mathrm{N}$ removed over a 30-year technology lifespan) in the Status quo scenario. A higher mean cost-efficiency shown in the figure equals more nitrogen removed per dollar spent. 
Confidential manuscript submitted to Journal of Environmental Management; Harris-Lovett, Lienert, Sedlak

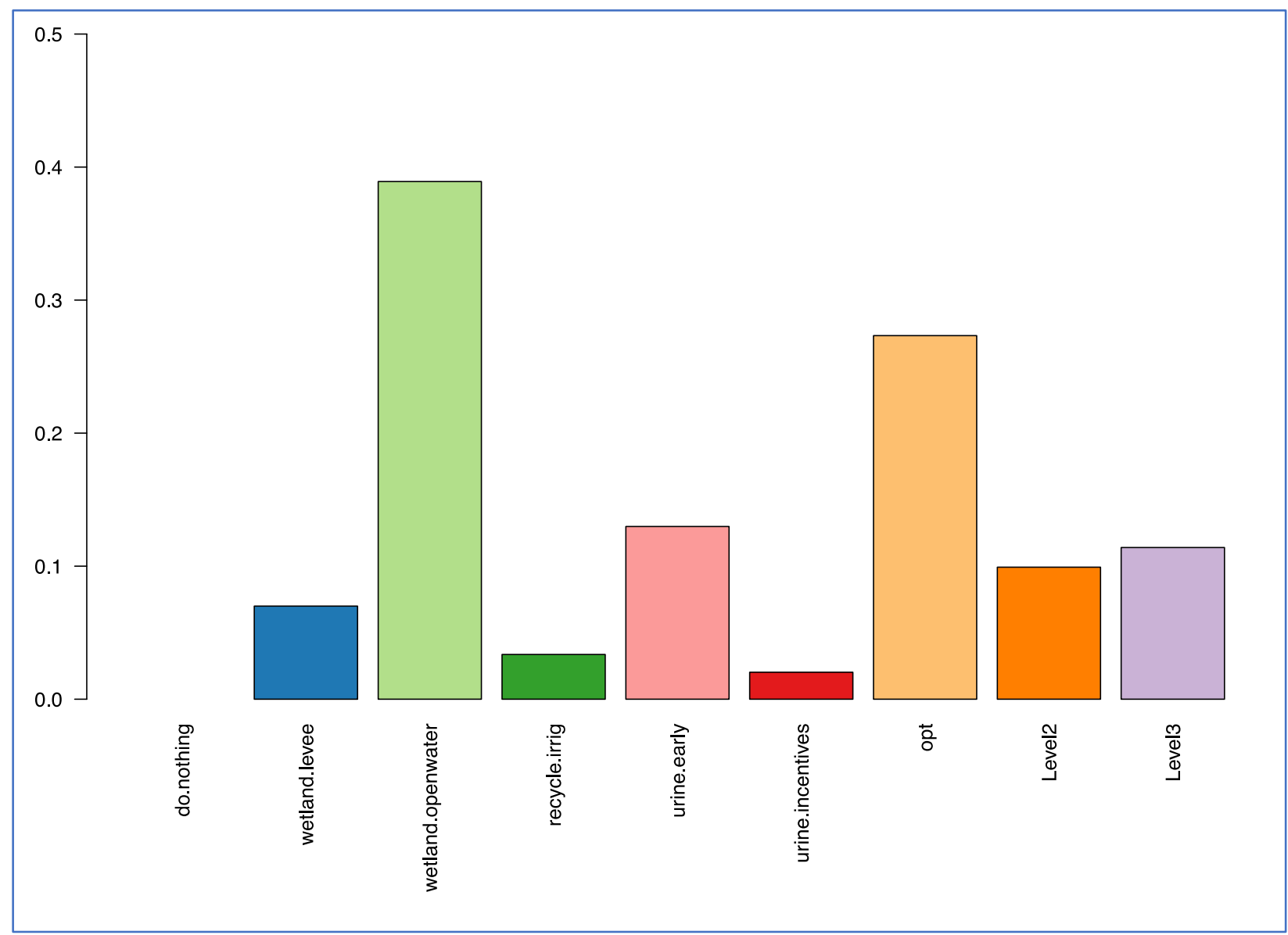

Figure 7. Mean cost-efficiency ( $k g$ of nitrogen removal/\$) for each option, Status quo scenario.

Open water wetlands (light green) and optimization (light orange) performed well in the cost-efficiency metric. Wetland levees and recycling for irrigation (which ranked highly for many stakeholders in the MCDA), scored relatively low in the cost-efficiency metric.

Although many stakeholders mentioned cost-efficiency as the "standard" method for choosing wastewater management options (i.e., the institutionally-sanctioned method) this was not reflected in the MCDA results for many stakeholders. We therefore analyzed the correlation between cost-efficiency and MCDA overall values for each option and stakeholder. Stakeholders exhibited a range in correlations between these two measures (Supplemental Information, Figure S9). Some stakeholders' preferences for non-traditional goals for nutrient management (which were captured in the MCDA), resulted in a negative correlation between cost-efficiency and MCDA results. Other stakeholders showed a positive correlation between cost-efficiency and MCDA overall value, signifying that they tended to value cost-efficient options in the MCDA.

\subsection{Sensitivity analysis}

\subsubsection{Thresholds}

Some stakeholders voiced acceptance thresholds (veto conditions) for particular attributes, below which an option would be unacceptable to them. Four stakeholders set thresholds in attribute levels for reliability, water quality, ease of adaptation, and resilience to sea level rise. Inclusion of these thresholds in MCDA calculations would change the overall value of 
Confidential manuscript submitted to Journal of Environmental Management; Harris-Lovett, Lienert, Sedlak

some options for four stakeholders and, in one case, make all options unacceptable. For example, for stakeholder SH4 with a reliability threshold at 70\% (any option with less than $70 \%$ reliability would not be acceptable), recycling for irrigation remained likely to rank highly, but wetland levees were split between ranking very highly (in the top 4 ranked options $74 \%$ of the time) and being unacceptable ( $26 \%$ of the time) due to the uncertainty about reliability of this technology for nutrient removal. Complete results of threshold analysis for all stakeholders with stated thresholds are in the Supplemental Information, Text S6.

\subsubsection{Aggregation functions}

We tested a range of aggregation variants combining additive aggregation with CobbDouglas aggregation (Supplemental Information, Figure S10) (as in Zheng et al., 2016). CobbDouglas aggregation tends to value options more highly that do not have extreme variation in levels of attribute fulfillment between objectives. Although the overall ranking of options remained similar for most stakeholders regardless of the aggregation type, aggregation variants with higher levels of Cobb-Douglas aggregation tended to result in lower overall value for traditional upgrades (which have high fulfillment of some objectives like reliability, ease of permitting and no fulfillment of objectives like shoreline access, increased water supply, or wetland habitat).

\subsubsection{Marginal value functions}

We tested the assumption of linear value functions with a sensitivity analysis of overall value for each option given different shapes of value functions for the objectives ease of adaptation, permitting, reliability, and water quality. These objectives were chosen because several stakeholders expressed mild-to-moderate concave curvatures for them in interviews. We tested a range of curvatures for these four objectives to assess how they affected the overall value of options for all stakeholders (Supplemental Information, Figure S11). Convex value functions imply greatest marginal overall value gained with improvement at low levels of attribute value. Concave value functions imply greatest marginal overall value gained with improvement at high levels of attribute value.

Mild-to-moderate concave value functions (what stakeholders expressed in interviews) had little effect on overall ranking of options for any stakeholder. In contrast, convex value functions vaulted the "Do nothing" option to the forefront for many stakeholders.

\subsubsection{Weight of the objective category "total cost"}

It is possible that stakeholders responded in interviews about the weights of different objectives in ways that did not reflect their true weights in the decision-making process. In particular, many stakeholders seemed to minimize the costs of nutrient management options in comparison to other objectives during interviews. While this may have reflected their feelings, it could also have been a result of trying to answer in a way in which they thought the researcher would appreciate (i.e., social desirability bias) (Nederhof, 1985). MCDA researchers have noted interview participants tend to weigh objectives at approximately $1 / n$, where ' $n$ ' is the number of objectives (Marttunen et al., 2018). This bias holds true for the 'low cost objective', where the median cost weight was 0.073 , which is approximately equal to $1 / 13(0.077)$.

Given the strong institutional mandate for minimizing costs for both dischargers and regulators (Harris-Lovett et al., 2018), we increased weights for the objective category "total costs" by $25 \%$ (and re-scaled other weights accordingly) to see how these changes influenced 
Confidential manuscript submitted to Journal of Environmental Management; Harris-Lovett, Lienert, Sedlak

overall values of different options in the Status quo scenario (Supplemental Information, Figure $\mathrm{S} 12)$. This resulted in an increase in the median overall value of the "Do nothing" option for many stakeholders, though the ranking of the top option for most stakeholders did not change.

\section{Discussion}

4.1 Implications of MCDA results for nutrient management in the San Francisco Bay case study

The results of the MCDA provide several interesting insights. First, increasing wastewater recycling for irrigation is an option that ranks among the top three for many stakeholders regardless of future conditions (Figure 5; Supplemental Information, Figures S4S8), because it increases water supply and utilizes nutrients in the waste stream for fertilizer (as exemplified for one stakeholder in Figure 6). This option remained attractive to many stakeholders despite the higher costs per unit of nitrogen removed than many of the other options (Figure 7). Though recycling for irrigation can be expensive - and in some cases has been considered prohibitively so (Bischel et al., 2012) - it may be seen as a viable option if it also prevents nitrogen discharge to sensitive water bodies, because stakeholders' considerations of value go beyond the monetary costs.

Regarding nutrient management, recycling wastewater for irrigation is far superior to recycling wastewater for potable reuse, because nutrients are not removed from irrigation water prior to reuse. Potable water reuse requires safe disposal of concentrate generated during reverse osmosis treatment. Diverting this concentrate away from sensitive water bodies like the Bay is a significant barrier in terms of costs and greenhouse gas emissions (for pumping brine to the ocean). Treatment technologies to remove nutrients from reverse osmosis concentrate are currently being developed, but most have not been proven in full-scale systems (Umar et al., 2015; Pérez-González et al., 2012). If effective treatment options to remove nutrients from brine were available, potable water reuse could become a more feasible option for nutrient management.

Construction of treatment wetlands (horizontal levees) for nutrient treatment also ranked highly for many stakeholders in various uncertain futures (Figures 5; S4-S8). Additional wetland habitat, increased resilience to sea level rise, shoreline access, and treatment of contaminants of emerging concern favored this option for many stakeholders in the MCDA despite a very low cost-efficiency ratio (Figure 7). Because this is a relatively new approach, there is a distinct possibility that the cost will be reduced as designers gain more experience with the construction and operation of the system. Furthermore, additional experience will decrease uncertainty about system performance.

A lack of familiarity with urine source-separation technology is a likely explanation for the low ranking of this option by most stakeholders. In contrast to the United States, this technology has gained more credibility in Switzerland and Scandinavia (Lienert and Larsen, 2009). If urine source-separation were more popular among the public (i.e., if it did not require financial incentives to encourage adoption), it would likely be a very cost-effective way to avoid the discharge of nitrogen to the Bay. Additionally, it provides the added benefits of recovering nutrients from sewage for use as fertilizer and of being more easily adaptable to changing conditions because it is easily adapted to expansion as the need to remove more nitrogen increases. To advance this potentially attractive option, pilot projects to increase public awareness and identify conditions affecting its performance in the United States would be helpful. 
Confidential manuscript submitted to Journal of Environmental Management; Harris-Lovett, Lienert, Sedlak

It is likely that upgrades to existing treatment plants would be deployed only in response to regulations related to nutrient loading, because the main benefit of these options is nutrient control. In contrast, multi-benefit options, like increased recycling of wastewater for irrigation and construction of horizontal levees, provide benefits that were ranked more highly than the upgrades or the 'Do nothing' option for most stakeholders even under the Best-case scenario, where there is decreased pressure for nutrient loading to cause adverse ecological effects (Figure S5).

The overall value for many of the nutrient management options is relatively low (scoring under 0.5) for many stakeholders in the Status quo and Worst-case scenarios. This indicates that in the absence of the Best-case scenario, no single option is likely to meet stakeholder goals. It is important to note that these options are not mutually exclusive - for example, optimization and constructed wetlands could both be implemented at the same wastewater treatment plant resulting in much lower concentrations of nutrients being released to the Bay. Combinations could provide effective ways to meet more objectives under less-desirable future scenarios.

\subsection{Sensitivity analysis}

Acceptability thresholds in criteria mentioned by several stakeholders would greatly influence the ranking of options and would remove many options from consideration in any future scenario (see similar observation and discussion in Scholten et al., 2015). This suggests that further discussion about thresholds is necessary to determine how stakeholders would react to an exceeded threshold (e.g., litigation, disapproval of project, removal of funding). Efforts to limit scientific uncertainty should focus on areas where stakeholders have stated thresholds (e.g., likelihood of deviation from good water quality, resilience to sea level rise, reliability, and ease of adaptation to changing conditions) to provide better estimates of how well different management options perform in each of these categories. Additionally, options that do not exceed stakeholders' stated thresholds should be developed. Technically, such acceptability thresholds can be modeled by minimum aggregation (e.g., Langhans et al., 2014). However, for the purposes of evaluating options for regional environmental management as in the case study, assumed additive aggregation likely provides sufficient insight into management options because rankings were largely unchanged for most stakeholders.

The results of a MCDA (the total value and ranking of options) can be highly sensitive to stakeholders' weights, which is why elicitation of this preference parameter is often critical. In this case study, the weights for "total costs" were lower than researchers expected (median of 0.07; Harris-Lovett et al., 2018). This is in line with a recent meta-analysis concerning weight elicitation procedures in environmental MCDA cases, where economic objectives usually received lower weights than environmental and social objectives (Marttunen et al., 2018). Because interviewees might not fully express institutional economic constraints or other stakeholders might place a higher value on economic objectives, sensitivity analysis for this parameter is worth considering. Increasing the weight for "total cost" by $25 \%$ increased the overall value and rank of the "Do nothing" option for many stakeholders. This finding is significant because it encourages reflection by decision-makers and policy-makers. Specifically, stakeholders need to consider the likelihood that they can convince their institutions to overcome a traditional focus on low-cost solutions in order to pursue other goals, which may fall outside of their mandated responsibility (e.g., a wastewater utility funding shoreline access or increased water supply). Further alignment of decision-makers' institutional mandates with their goals for 
Confidential manuscript submitted to Journal of Environmental Management; Harris-Lovett, Lienert, Sedlak

multi-benefit water infrastructure projects would reduce the uncertainty related to the ability of stakeholders to follow through on their stated priorities.

\subsection{MCDA process integrated with stakeholder analysis and scenario planning}

Many useful insights to decision-making about water infrastructure and environmental management more broadly can be gained from integrating MCDA with stakeholder analysis and scenario planning. MCDA paired with stakeholder analysis sheds light on the ways in which different stakeholders who must collaborate on regional infrastructure projects would value various management options. The addition of scenario planning to MCDA elucidates how management options fare in different possible futures. These insights can help avoid costly investments in infrastructure that may be more controversial or less resilient to future conditions. Many stakeholders in this case have expressed interest in the results. This mixed-methods approach is a promising decision-support tool for other problems in regions that require largescale collaboration with multiple stakeholders for long-term infrastructure planning and development.

R software was especially useful for combining MCDA with scenario planning, since it allows to easily shift baseline assumptions about the performance of various management options in the MCDA calculations. Additionally, open-source software like R makes the calculations more transparent and enables stakeholders to vary the future scenario conditions (with more or less population growth, for example) to see how that would affect MCDA results.

However, the mixed-methods approach has several limitations. Policy-makers charged with environmental management tend to be averse to complex assessments like these, rather tending to selecting options that are economically efficient and have low risks (Starkl et al., 2009). Furthermore, time-intensive, in-person interviews with stakeholders may not always be possible (Marttunen and Hämäläinen, 2008). Analysis of qualitative interview data in conjunction with quantitative MCDA requires support of analysts who are versed in multiple methods of inquiry. Finally, without developing a definite 'answer' to the challenge of environmental management it may be unclear to stakeholders how to use the MCDA results to reach consensus in practice especially if the research protocol anonymizes the contributions of different stakeholders and thus de-personalizes the results.

A summary of the methods employed in this study, along with their advantages and disadvantages, are in Table 5.

Table 5. Methods integrated into the standard MCDA process to support regional decisionmaking for multi-benefit infrastructure.

\begin{tabular}{|l|l|l|l|}
\hline Step & Methods & Advantage & Disadvantage \\
\hline $\begin{array}{l}\text { Initial } \\
\text { stakeholder } \\
\text { selection }\end{array}$ & $\begin{array}{l}\text { Broad outreach to people and } \\
\text { organizations who have } \\
\text { authored documents or } \\
\text { participated in public } \\
\text { meetings related to nutrient } \\
\text { management }\end{array}$ & $\begin{array}{l}\text {-Includes perspectives } \\
\text { of those who have been } \\
\text { publicly working on } \\
\text { the issue }\end{array}$ & $\begin{array}{l}\text {-Not necessarily clear whom to } \\
\text { include within an organization } \\
\text {-Stakeholders with less time or } \\
\text { influence, who may still have } \\
\text { strong feelings about the issue, } \\
\text { are not included }\end{array}$ \\
\cline { 2 - 4 } & Snowball sampling & $\begin{array}{l}\text {-Personal referrals to } \\
\text { targeted individuals } \\
\text {-Gain insight into } \\
\text { identity of influential } \\
\text { stakeholders }\end{array}$ & $\begin{array}{l}\text {-Can lead to sampling within a } \\
\text { bubble' of people with similar } \\
\text { ideas or professional roles, } \\
\text { might neglect important } \\
\text { stakeholders from other }\end{array}$ \\
\hline
\end{tabular}


Confidential manuscript submitted to Journal of Environmental Management; Harris-Lovett, Lienert, Sedlak

\begin{tabular}{|c|c|c|c|}
\hline Step & Methods & Advantage & Disadvantage \\
\hline & & & professional fields or regions \\
\hline & $\begin{array}{l}\text { Inclusion of stakeholders } \\
\text { whom researchers deemed } \\
\text { would be affected by nutrient } \\
\text { management but who were } \\
\text { not involved in authoring } \\
\text { documents, public meetings, } \\
\text { or recommended by other } \\
\text { interviewees }\end{array}$ & $\begin{array}{l}\text {-Can include } \\
\text { perspectives of } \\
\text { marginalized groups } \\
\text { who have not } \\
\text { traditionally been } \\
\text { included in decision- } \\
\text { making about water } \\
\text { infrastructure }\end{array}$ & $\begin{array}{l}\text {-Researchers may not be able } \\
\text { to accurately predict who } \\
\text { would be affected }\end{array}$ \\
\hline $\begin{array}{l}\text { Selection of } \\
\text { stakeholders } \\
\text { for MCDA } \\
\text { preference } \\
\text { elicitation } \\
\text { interviews }\end{array}$ & $\begin{array}{l}\text { Cluster analysis based on } \\
\text { stated goals for nutrient } \\
\text { management in initial } \\
\text { interviews, followed by } \\
\text { stratified sampling to choose } \\
\text { those stakeholders most } \\
\text { relevant to decision-making } \\
\text { from each cluster }\end{array}$ & $\begin{array}{l}\text {-Broad representation } \\
\text { of stakeholders with } \\
\text { different goals } \\
\text {-Does not assume } \\
\text { stakeholders with same } \\
\text { professional role } \\
\text { necessarily have the } \\
\text { same goals }\end{array}$ & $\begin{array}{l}\text {-May over- or under-represent } \\
\text { stakeholders from any } \\
\text { particular professional role }\end{array}$ \\
\hline $\begin{array}{l}\text { Identify } \\
\text { objectives } \\
\text { and attributes }\end{array}$ & $\begin{array}{l}\text { Solicitation of objectives and } \\
\text { attributes from individual } \\
\text { stakeholders (rather than } \\
\text { focus groups or stakeholder } \\
\text { workshops) }\end{array}$ & $\begin{array}{l}\text {-Encourages } \\
\text { participation from } \\
\text { stakeholders with less } \\
\text { influence or political } \\
\text { power } \\
\text {-Identifies areas of } \\
\text { disagreement and } \\
\text { agreement among } \\
\text { stakeholders }\end{array}$ & $\begin{array}{l}\text {-Differences in language } \\
\text { among different stakeholders } \\
\text { may result in researcher } \\
\text { misinterpretation of objectives } \\
\text { and attributes } \\
\text {-No consensus reached on } \\
\text { objectives and attributes }\end{array}$ \\
\hline & $\begin{array}{l}\text { Researcher synthesis of } \\
\text { objectives and attributes }\end{array}$ & $\begin{array}{l}\text {-Encourages the } \\
\text { inclusion of objectives } \\
\text { from stakeholders with } \\
\text { less influence or } \\
\text { political power }\end{array}$ & $\begin{array}{l}\text {-May result in disagreement } \\
\text { about the accuracy of } \\
\text { attributes for describing } \\
\text { objectives } \\
\text {-Choices about structuring the } \\
\text { objectives hierarchy can bias } \\
\text { stakeholder weights }\end{array}$ \\
\hline & Limited objectives to $<15$ & $\begin{array}{l}\text {-Ease of mental } \\
\text { processing for } \\
\text { stakeholders } \\
\text {-Less time required for } \\
\text { elicitation }\end{array}$ & $\begin{array}{l}\text {-Possible consolidation of } \\
\text { objectives that some } \\
\text { stakeholders consider distinct }\end{array}$ \\
\hline & $\begin{array}{l}\text { Researchers generated } \\
\text { objectives that helped } \\
\text { differentiate between } \\
\text { management options }\end{array}$ & $\begin{array}{l}\text {-Assisted with } \\
\text { differentiation between } \\
\text { specific management } \\
\text { options in the MCDA }\end{array}$ & $\begin{array}{l}\text {-May be less relevant to } \\
\text { stakeholders than some of the } \\
\text { other objectives }\end{array}$ \\
\hline $\begin{array}{l}\text { Development } \\
\text { of future } \\
\text { scenarios }\end{array}$ & $\begin{array}{l}\text { Informed by stakeholder } \\
\text { ideas about "critical } \\
\text { uncertainties" that would } \\
\text { affect nutrient management }\end{array}$ & $\begin{array}{l}\text {-Takes into account the } \\
\text { uncertainties } \\
\text { stakeholders are } \\
\text { considering }\end{array}$ & $\begin{array}{l}\text {-Does not take into account } \\
\text { unforeseen situations that } \\
\text { could strongly affect future } \\
\text { conditions }\end{array}$ \\
\hline & $\begin{array}{l}\text { Used scenario generation } \\
\text { matrix to develop Best- and } \\
\text { Worst-case scenarios }\end{array}$ & $\begin{array}{l}\text {-Bounds uncertain } \\
\text { futures within the areas } \\
\text { specified }\end{array}$ & $\begin{array}{l}\text {-Best- and Worst-case } \\
\text { scenarios may be less useful } \\
\text { for prescriptive MCDA when }\end{array}$ \\
\hline
\end{tabular}


Confidential manuscript submitted to Journal of Environmental Management; Harris-Lovett, Lienert, Sedlak

\begin{tabular}{|c|c|c|c|}
\hline Step & Methods & Advantage & Disadvantage \\
\hline & & & choosing management options \\
\hline $\begin{array}{l}\text { Development } \\
\text { of } \\
\text { management } \\
\text { options }\end{array}$ & $\begin{array}{l}\text { Illustrative options applied at } \\
\text { their maximum extent to the } \\
\text { whole region, rather than } \\
\text { more realistic combinations } \\
\text { of options or site-specific } \\
\text { options within the region }\end{array}$ & $\begin{array}{l}\text {-Highlights ways in } \\
\text { which different } \\
\text { management options } \\
\text { can fulfill different } \\
\text { stakeholder objectives }\end{array}$ & $\begin{array}{l}\text {-Is not realistic, does not } \\
\text { provide a prescriptive set of } \\
\text { actions }\end{array}$ \\
\hline $\begin{array}{l}\text { Predict } \\
\text { outcomes of } \\
\text { each option, } \\
\text { given } \\
\text { uncertainty } \\
\text { about the } \\
\text { future }\end{array}$ & $\begin{array}{l}\text { Estimated range of values and } \\
\text { distribution for attributes } \\
\text { from the literature, from } \\
\text { expert opinion, and modeled } \\
\text { from previous technology } \\
\text { implementation }\end{array}$ & $\begin{array}{l}\text {-Approximates } \\
\text { uncertainty in attribute } \\
\text { values for all objectives } \\
\text {-Elucidates magnitude } \\
\text { of differences in } \\
\text { MCDA results due to } \\
\text { uncertainty in technical } \\
\text { attribute prediction } \\
\text { versus future scenario } \\
\text { conditions }\end{array}$ & $\begin{array}{l}\text {-Distribution of uncertainty } \\
\text { could be incorrect } \\
\text {-Attribute values from the } \\
\text { literature and past } \\
\text { implementation may be quite } \\
\text { different from local values due } \\
\text { to local conditions }\end{array}$ \\
\hline \multirow[t]{3}{*}{$\begin{array}{l}\text { Elicitation of } \\
\text { stakeholder } \\
\text { preferences } \\
\text { (weights and } \\
\text { marginal } \\
\text { value } \\
\text { functions) }\end{array}$} & $\begin{array}{l}\text { Used notecards of objectives } \\
\text { stakeholders could physically } \\
\text { move around on the table to } \\
\text { represent preference weights } \\
\text { for Swing method elicitation }\end{array}$ & $\begin{array}{l}\text {-Allows for kinetic } \\
\text { experience of the } \\
\text { weightings } \\
\text {-Stakeholders can } \\
\text { easily re-arrange to } \\
\text { 'try' different weights } \\
\text { and see what seems } \\
\text { most accurate }\end{array}$ & $\begin{array}{l}\text {-Requires in-person interviews } \\
\text {-Time intensive }\end{array}$ \\
\hline & $\begin{array}{l}\text { Did not include stakeholder } \\
\text { uncertainty in preference } \\
\text { weights or consideration of } \\
\text { differences in weights from a } \\
\text { personal vs. professional } \\
\text { perspective }\end{array}$ & $\begin{array}{l}\text {-Simplifies MCDA } \\
\text {-Less time-intensive }\end{array}$ & $\begin{array}{l}\text {-May inaccurately represent } \\
\text { stakeholder preferences }\end{array}$ \\
\hline & $\begin{array}{l}\text { Used bi-section method to } \\
\text { elicit marginal value } \\
\text { functions }\end{array}$ & $\begin{array}{l}\text {-Has the potential to } \\
\text { provide rough } \\
\text { curvature estimates } \\
\text { with little elicitation } \\
\text { time }\end{array}$ & $\begin{array}{l}\text {-May result in vague, non- } \\
\text { quantitative results due to } \\
\text { political nature of making } \\
\text { some values explicit or time } \\
\text { constraints }\end{array}$ \\
\hline $\begin{array}{l}\text { Integrate } \\
\text { preference } \\
\text { weights and } \\
\text { attribute } \\
\text { predictions to } \\
\text { rank options }\end{array}$ & $\begin{array}{l}\text { Performed rankings for all } \\
\text { stakeholders separately, did } \\
\text { not use aggregate by using } \\
\text { average weights }\end{array}$ & $\begin{array}{l}\text {-Identifies the range of } \\
\text { stakeholder opinions } \\
\text {-Identifies areas of } \\
\text { conflict and agreement } \\
\text { amongst stakeholders }\end{array}$ & $\begin{array}{l}\text {-Complex to analyze and } \\
\text { interpret results } \\
\text {-No clear 'answer' from the } \\
\text { MCDA regarding a consensus } \\
\text { solution; this would require } \\
\text { further stakeholder workshops }\end{array}$ \\
\hline
\end{tabular}


Confidential manuscript submitted to Journal of Environmental Management; Harris-Lovett, Lienert, Sedlak

\subsubsection{Choice of stakeholders}

When MCDA is applied to a complex problem involving regional environmental management, it is difficult to choose suitable stakeholders. Because the analysis is affected by stakeholder preferences, this selection process is crucial. This problem is common in decisionmaking or strategic planning situations in which there is a desire for stakeholder engagement. However, it remains a salient issue, though best practices include efforts to include those affected by decisions as well as decision-makers and expanding beyond the 'usual suspects' (see for example, Colvin et al., 2016; Reed et al., 2009; Achterkamp and Vos, 2007; Vos and Achterkamp, 2006; Bryson, 2004; Mitchell et al., 1997). It is also noteworthy that stakeholder choice will vary over time; stakeholders who are currently most important to and most affected by decision-making may change (Brugha and Varvasovszky, 2000). This was evident even in this case study. Several people who participated in the first set of interviews changed jobs by the time the follow-up interviews occurred several months later.

Our method of stakeholder selection emphasized diversity of opinion and profession. Despite our efforts to obtain a broad range of opinions, many of our chosen stakeholders were technical experts or represented government/ municipal agencies. This tendency to emphasize the opinions of such experts has been observed in previous MCDA studies (Soltani et al., 2015). For example, several groups that might have expressed different perspectives were not included in the interviews (e.g., homeowners and renters, subsistence fishers, farmers who might use recycled water for irrigation) because they were less actively engaged in the issue.

In addition, after an organization was positively identified as a "stakeholder", the most appropriate person to interview was not always evident (e.g., managers versus board members). Other researchers have also noted that transparent methods to select and engage stakeholders in a participatory MCDA process are not available (Marttunen et al., 2015). Further research to improve the stakeholder identification process, especially for application to regional environmental MCDA, would be a useful contribution to the field.

Clustering and selecting participants for follow-up interviews based on their goals for nutrient management and their involvement with the issue clarified the differences in objectives amongst people with similar professional roles. Because we deliberately chose stakeholders who reflected a range of opinions, some participants expressed opinions that may be considered as outliers. The importance of this sampling method was validated in interviews, where several participants expressed the opinion that individuals with strong opinions could have an outsize effect on the decision-making process through litigation or soliciting media attention.

The cluster analysis informed the selection of participants for second-round interviews who had a range of viewpoints and who were most relevant to decision making. The fact that all stakeholders who were asked to participate in follow-up interviews agreed to do so, despite the significant time investment (see Section 4.3.4), confirms the relevance of the clustering methodology for stakeholder selection.

\subsubsection{Identification of objectives and attributes}

Identifying objectives and attributes based on interviews yielded essential information, but the process was not always orderly. Similarly worded objectives could have different meanings to participants. As a result, we were forced to make subjective decisions to condense the plethora of stated objectives into a manageable set (Harris-Lovett et al. 2018). Additionally, we made subjective choices to categorize objectives (e.g., 'ease of permitting' could have fit into 
Confidential manuscript submitted to Journal of Environmental Management; Harris-Lovett, Lienert, Sedlak

the categories of 'low costs' or 'social support'). These choices could affect weighting of the objectives, depending on how many other objectives were in the category and whether they emphasized social or economic values (Marttunen et al., 2018). Providing participants with a list of potential objectives and allowing them to place them into categories (after they came up with their own objectives) might allow researchers to standardize differences in understanding of language among stakeholders.

It was also difficult to identify measureable attributes for each objective. Others recommend stakeholder workshops to develop such attributes (Eisenführ et al., 2010; Belton and Pictet, 1997; Massey and Wallace, 1996). However, such a time-consuming process might not be feasible or agreeable to all participants. As an alternative, we developed our objectives based on ideas expressed by individual stakeholders during the interviews. An advantage is that this allowed individuals with less decision-making influence to have their opinions incorporated into the study design.

Despite these challenges, defining the objectives hierarchy and selecting measurable attributes were some of the most instructive steps of the MCDA process. Vagueness of stated objectives in interviews and discrepancies among opinions about proper attributes to measure fulfillment of each objective are areas where further research and discussion amongst stakeholders may be beneficial. In this case study, these included a need for developing technologies for nutrient management that are easily adaptable to changing conditions and clearly defining criteria for nutrient-related impairment to the San Francisco Bay ecosystem.

\subsubsection{Choice of management options}

Generating management options is considered an integral part of the "problem structuring" aspect of MCDA (Belton and Stewart, 2002). Other MCDA analysts suggest choosing options that emphasize fulfillment of different objectives (Pereira et al., 1994). In environmental decision-making, researchers have emphasized the importance of ensuring stakeholder participation and including both standard and innovative options (Lahdelma et al., 2000). However, little guidance exists for determining the scale of the options that need to be considered in regional environmental decisions. In this case study, it was not clear whether the MCDA problem should be considered at the scale of a single wastewater treatment plant (much simpler to analyze) or for the whole southern reach of the Bay (complex but more relevant to actual decision-making). At an early point in the environmental decision-making process about a regional challenge (before any regulations have been set, in this case about nutrient loading), and with so many quasi-independent decision-makers, it is difficult to develop options to model with MCDA that accurately represent actual management options.

To simplify this problem, we applied each option uniformly across wastewater treatment plant service areas. This highlights the general benefits, drawbacks, and discussion points of each management option, but does not provide personalized guidance to wastewater treatment plant managers about the specific options that would be optimal for their situation. Further research is needed to assess whether this approach yields results that are substantially different from MCDAs that consider multiple smaller-scale options for different areas within a larger region. Comparison of MCDA results using modeled regional management options to local ones would be one way of conducting such further research.

\subsubsection{Elicitation of stakeholder preferences}


Confidential manuscript submitted to Journal of Environmental Management; Harris-Lovett, Lienert, Sedlak

To evaluate the reliability of stakeholders' weights for objectives derived from the Swing elicitation process, they were asked: "How much did you take into account the worst and best values of each goal when you decided on the swings?" (Harris-Lovett et al., 2018). Seven stakeholders answered (two did not because of time constraints), but only one chose the response option: "They were essential to my decision." Four responded: "I took them into consideration", and two: "I didn't consider them". Range insensitivity is well-known in the MCDA literature (Clemen and Reilly, 2004). To assure accurate results, weight elicitation methods rely upon respondents' careful deliberation of the worst-best attribute range (Eisenführ et al., 2010). Although this requirement might have been violated to some extent in our case, the elicitation process may still have been useful for decision-makers (Marttunen and Hämäläinen, 2008). One reason is that people often form their preferences in the process of assigning weights (Belton and Stewart, 2002), so weight elicitation helps decision-makers clarify what is important to them.

It is good practice to carry out consistency checks of elicited weights with another method; the trade-off method can serve as an alternative to the Swing method (Eisenführ et al., 2010). Despite its strong theoretical foundation (Keeney and Raiffa, 1976) and its usefulness in defining stakeholder preferences in MCDA for environmental management (Reichert et al., 2015), we found the trade-off weight elicitation method to be ineffective in practice. All stakeholders were unwilling to express numerical trade-offs between attributes (e.g., "Paying $\$ 200,000$ to reduce the risk of impairing water quality by $5 \%$ is better than paying $\$ 600,0000$ to reduce the risk of impairing water quality by $20 \%$ "). These types of value statements are cognitively difficult, as well as highly political. Explicit identification of trade-offs may heighten conflict and lower confidence in decision-making (Kottemann and Davis, 1991). This could explain the reluctance of decision-makers to accept this premise in the interview process. Although some MCDA analysts have successfully employed the trade-off method in similar contexts (Anderson et al., 2001), our experience was consistent with that of researchers who found many stakeholders reluctant to express numeric values for trade-offs (Zheng et al., 2016).

Similarly, we found marginal value functions difficult to elicit with the bisection method ("Improvement from the worst value to a middle-value point is perceived as equally beneficial as improvement from a middle-value point to the best value"). These questions were almost uniformly met with vague, non-quantitative responses, possibly due to time constraints or an inability to give numeric values for complex decisions. Some of the difficulty may have been due to the relative inexperience of the researcher conducting MCDA interviews (Pöyhönen and Hämäläinen, 2000). The sensitivity analysis indicates that differences in marginal value function curvatures (particularly for convex value functions) could drastically change the overall value of options for many stakeholders. Therefore, avoiding the difficulties by assuming linearity of value functions would be inadequate for this case (e.g. Langhans and Lienert, 2016; Zheng et al., 2016). Thus, other methods of eliciting marginal value functions would have been needed to accomplish these goals.

We found that allocating one hour for follow-up interviews for preference elicitation was not always sufficient. This poses a problem for MCDA interviews because many high-level decision-makers have busy schedules; an observation shared by many researchers implementing MCDA. We recommend that future research should focus on developing tools that allow for reliable preference elicitation in a more efficient manner. One idea receiving increasing interest is adaptive elicitation, where specific answers of the decision-maker determine the questions that are asked next. This could considerably reduce the length of the interview (Ciomek et al., 2017; de Almeida et al., 2016). 
Confidential manuscript submitted to Journal of Environmental Management; Harris-Lovett, Lienert, Sedlak

Our experiences suggest that the main insights gained from the elicitation of stakeholder preferences are qualitative, and are obtained from conversation about the value of different objectives. For example, attempts to elicit bi-section values for the objective 'reliability' led to reflections about reliability for wastewater management in general, compared to nutrient management in particular. Reliability close to $100 \%$ is desirable for controlling pathogens, because any lapse can potentially affect public health. In contrast, occasional periods of high nutrients concentrations in effluent due to lapses in reliability are not likely to be ecologically detrimental if their duration is limited.

Another issue raised during the interview process was a tension between personal values, professional roles, and institutional mandates. For example, several stakeholders mentioned that they personally valued wetland habitat highly but that this was not within the scope of their professional role. To obtain results that were most reflective of the actual decision-making process, we asked stakeholders to weight criteria based on whatever value (personal or professional) would affect their professional decision-making. However, this made it difficult for several stakeholders to answer the questions. Future MCDA procedures could include elicitation of value judgements both as a private person and as an official representative, with sensitivity analysis to compare any differences in results. Additionally, a greater sociological understanding of how private values influence professional actions in regional environmental decision-making would provide insight into the importance of this potential conflict.

\subsubsection{Addressing uncertainty of stakeholder preferences, future scenarios, and attribute predictions}

We opted to keep stakeholder weights separate, rather than aggregate them. This allowed to highlight the diversity of opinions and to assess management options ranked highly by multiple stakeholders (Gregory et al., 2001; Matsatsinis and Samaras, 2001; Belton and Pictet, 1997). However, the disaggregated results do not provide decision-makers with a consensus or a clear path forward. Instead, they raise questions about the importance of opinions held by different stakeholders. Because the MCDA research protocol precludes identification of the stakeholders who express opinions that deviate from the larger group, disaggregated group results only provide information about disagreements that may require attention. In situations where disparate opinions are observed, follow-up stakeholder workshops could be used to promote discussion and build consensus (Ferguson et al., 2013).

Future scenarios were selected to illustrate the robustness of MCDA options in the year 2050 (Marttunen et al., 2017). By designing future scenarios with the "critical uncertainties" stakeholders mentioned, we aimed to capture the range of future possibilities that would likely have the biggest impact on nutrient management. However, this approach considers only the "known-unknowns" - and none of the "unknown-unknowns". "Unknown-unknowns" could originate in another sector entirely (e.g., regulations on greenhouse gas emissions) and could deeply constrain wastewater treatment operations by making a specific technology much less attractive, for example. Characterization of potential "unknown-unknowns" and analysis of the MCDA results under these less-predictable conditions could enhance the reliability of the MCDA.

Including uncertainty in attribute predictions in the MCDA highlighted the ways in which uncertainty about technical performance of the management options could affect outcomes ( Zheng et al., 2016; Durbach and Stewart, 2012). This strategy was especially useful in combination with analyzing the MCDA under different future scenarios because it allowed for 
Confidential manuscript submitted to Journal of Environmental Management; Harris-Lovett, Lienert, Sedlak

differentiation between uncertainty that cannot be controlled (future conditions) and uncertainty that can be minimized by collecting additional data (attribute predictions). In this case study, minimizing uncertainty related to attribute predictions would have a large effect on clarifying rankings of outcomes, because several options for stakeholders spanned very different ranks (from $1^{\text {st }}$ to $6^{\text {th }}$, for example) depending on attribute predictions (Supplemental Information, Figures S6-S8). Future scenarios, in contrast, largely changed overall values for options rather than their relative ranking (Supplemental Information, Figure S3).

\section{Conclusions}

The use of stakeholder analysis, MCDA and scenario planning in the San Francisco Bay case study provided insight into several critical areas. Stakeholders with similar professional roles (e.g., dischargers) often held different objectives for "good nutrient management", which implies that sampling methodologies for gaining stakeholder input should go beyond sampling people in different professional roles. Our results illuminated that the nutrient management option of increased recycling of wastewater for irrigation performed highly by most stakeholders regardless of future conditions, because it increased water supply. Likewise, constructed treatment wetlands performed well, because of their multiple benefits like increased wildlife habitat, resilience to sea level rise, and treatment of contaminants of emerging concern.

Employing a mixed-methods approach to strategic planning in water infrastructure development and other environmental management provides useful support to the decisionmaking process. Stakeholder analysis and MCDA paired with analysis of future uncertainties can integrate stakeholders' perspectives into formulating goals for environmental decision-making, and assess the ways in which different management options fulfill these goals. These methods can highlight areas of agreement and disagreement amongst stakeholders, laying the groundwork for discussion, collaboration, and consensus building. They can differentiate between the uncertainties over which decision-makers have little control (e.g., future conditions) and the uncertainties which additional data collection, research and development can help minimize (e.g., modeled attribute predictions). Additionally, these methods can incorporate the perspectives of potentially important stakeholders who may have been excluded from traditional decision processes.

Integrating stakeholder analysis, MCDA, and scenario planning can support regional environmental decision-making and merits further research. Our method of applying cluster analysis to select stakeholders for in-depth MCDA interviews, rather than selection based solely on their professional role, could be further refined in other research contexts. Explicit consideration of who has been included, and why, in group decision analyses for water infrastructure planning and environmental management could illuminate other methods for selecting stakeholders to participate in different stages of the MCDA and clarify for researchers the most appropriate method(s) for their own research. This type of review could support efforts to make environmental decision-making more equitable. Finally, testing and refining the combination of stakeholder analysis, MCDA, and scenario planning in other contexts, both for water infrastructure planning and for other environmental management options, would be a fruitful area for further inquiry.

\section{Acknowledgements}

The authors would like to thank all the interview participants for their time and thoughtful contributions to this research. We gratefully acknowledge the financial support from the NSF 
Confidential manuscript submitted to Journal of Environmental Management; Harris-Lovett, Lienert, Sedlak

Graduate Research Fellowship Program (SHL). This research was supported by the National Science Foundation (NSF) through the Engineering Research Center for Reinventing the Nation's Water Infrastructure (ReNUWIt) EEC-1028968. Declarations of interest: none.

\section{References}

Achterkamp, M.C., Vos, J.F., 2007. Critically identifying stakeholders. Syst. Res. Behav. Sci. 24, 3-14.

Al-Kloub, B., Al-Shemmeri, T., Pearman, A., 1997. The role of weights in multi-criteria decision aid, and the ranking of water projects in Jordan. Eur. J. Oper. Res. 99, 278-288. https://doi.org/10.1016/S0377-2217(96)00051-3

Alpine, A.E., Cloern, J.E., 1988. Phytoplankton growth rates in a light-limited environment, San Francisco Bay. Mar. Ecol. Prog. Ser. 167-173.

Anderson, D.M., Glibert, P.M., Burkholder, J.M., 2002. Harmful algal blooms and eutrophication: nutrient sources, composition, and consequences. Estuaries 25, 704-726.

Anderson, R., Hobbs, B., Koonce, J., Locci, A., 2001. Using Decision Analysis to Choose Phosphorus Targets for Lake Erie. Environ. Manage. 27, 235-252. https://doi.org/10.1007/s002670010146

Asano, T., Leverenz, H., Tsuchihashi, R., Tchobanoglous, G., 2007. Water Reuse: Issues, Technologies, and Applications, 1st ed. McGraw-Hill Professional.

Association of Bay Area Governments and the Metropolitan Transportation Commission, 2017. Plan Bay Area 2040 Draft Plan.

Association of Bay Area Governments, 2016. Regional Forecast for Plan Bay Area 2040. Available online at https://abag.ca.gov/planning/research/memos/Regional_Forecast_for_Plan_Bay_Area_2040_F_0 30116.pdf, accessed Oct. 3, 2018.

Atkinson, R., Flint, J., 2001. Accessing hidden and hard-to-reach populations: Snowball research strategies. Soc. Res. Update 33, 1-4.

Bachand, P.A.M., Horne, A.J., 1999. Denitrification in constructed free-water surface wetlands: I. Very high nitrate removal rates in a macrocosm study. Ecol. Eng. 14, 9-15. https://doi.org/10.1016/S0925-8574(99)00016-6

Balint, P.J., Stewart, R.E., Desai, A., 2011. Wicked Environmental Problems: Managing Uncertainty and Conflict. Island Press.

Batt, A.L., Kim, S., Aga, D.S., 2007. Comparison of the occurrence of antibiotics in four full-scale wastewater treatment plants with varying designs and operations. Chemosphere 68, 428-435. https://doi.org/10.1016/j.chemosphere.2007.01.008

Bay Area Census -- Bay Area Data [WWW Document], 2010. URL http://www.bayareacensus.ca.gov/bayarea.htm (accessed 9.13.17).

Belton, V., Pictet, J., 1997. A Framework for Group Decision Using a MCDA Model: Sharing, Aggregating or Comparing Individual Information? J. Decis. Syst. 6, 283-303. https://doi.org/10.1080/12460125.1997.10511726

Belton, V., Stewart, T., 2002. Multiple criteria decision analysis: an integrated approach. Springer.

Benda, L.E., Poff, L.N., Tague, C., Palmer, M.A., Pizzuto, J., Cooper, S., Stanley, E., Moglen, G., 2002. How to Avoid Train Wrecks When Using Science in Environmental Problem Solving. BioScience 52, 1127-1136. https://doi.org/10.1641/00063568(2002)052[1127:HTATWW]2.0.CO;2

Biernacki, P., Waldorf, D., 1981. Snowball sampling: Problems and techniques of chain referral sampling. Sociol. Methods Res. 10, 141-163.

Bischel, H.N., Simon, G.L., Frisby, T.M., Luthy, R.G., 2012. Management Experiences and Trends for Water Reuse Implementation in Northern California. Environ. Sci. Technol. 46, 180-188. https://doi.org/10.1021/es202725e 
Confidential manuscript submitted to Journal of Environmental Management; Harris-Lovett, Lienert, Sedlak

Bojórquez-Tapia, L.A., Sánchez-Colon, S., Florez, A., 2005. Building Consensus in Environmental Impact Assessment Through Multicriteria Modeling and Sensitivity Analysis. Environ. Manage. 36, 469-481. https://doi.org/10.1007/s00267-004-0127-5

Borcard, D., Gillet, F., Legendre, P., 2011. Numerical Ecology with R, 2011 edition. ed. Springer, New York.

Borsuk, M., Clemen, R., Maguire, L., Reckhow, K., 2001. Stakeholder Values and Scientific Modeling in the Neuse River Watershed. Group Decis. Negot. 10, 355-373. https://doi.org/10.1023/A:1011231801266

Boynton, W.R., Kemp, W.M., Keefe, C.W., 1982. A comparative analysis of nutrients and other factors influencing estuarine phytoplankton production, in: Estuarine Comparisons. Elsevier, pp. 69-90.

Brown, R., Farrelly, M.A., 2009. Delivering sustainable urban water management: a review of the hurdles we face. Water Sci. Technol. 59, 839-846.

Brugha, R., Varvasovszky, Z., 2000. Stakeholder analysis: a review. Health Policy Plan. 15, 239-246. https://doi.org/10.1093/heapol/15.3.239

Bryson, J.M., 2004. What to do when stakeholders matter: stakeholder identification and analysis techniques. Public Manag. Rev. 6, 21-53.

Carollo, 2014. City of San Mateo Integrated Wastewater Master Plan.

Carollo, Brown and Caldwell, SOM, 2008. Task No. 3, Project Memorandum No. 6, Historical and Project Service Area/Population.

CH2MHill and RMC, 2014. Palo Alto Regional Water Quality Control Plant Biosolids Facility Plan prepared for the City of Palo Alto, California.

Ciomek, K., Kadziński, M., Tervonen, T., 2017. Heuristics for prioritizing pair-wise elicitation questions with additive multi-attribute value models. Omega 71, 27-45.

City of Livermore, 2016. Livermore 2015 Urban Water Management Plan.

City of Palo Alto, 2008. City of Palo Alto Recycled Water Facility Plan.

City of Palo Alto Utilities, 2016. 2015 Urban Water Management Plan.

City of Sunnyvale, 2013. Feasibility Study for Recycled Water Expansion Report.

Clemen, R.T., Reilly, T., 2004. Making Hard Decisions with Decision Tools Suite Update Edition, 1 edition. ed. Cengage Learning, Pacific Grove, CA.

Cloern, J.E., 1999. The relative importance of light and nutrient limitation of phytoplankton growth: a simple index of coastal ecosystem sensitivity to nutrient enrichment. Aquat. Ecol. 33, 3-15.

Cloern, J.E., Jassby, A.D., 2012. Drivers of change in estuarine-coastal ecosystems: Discoveries from four decades of study in San Francisco Bay. Rev. Geophys. 50.

Cole, B.E., Cloern, J.E., 1984. Significance of biomass and light availability to phytoplankton productivity in San Francisco Bay. Mar. Ecol. Prog. Ser. 15-24.

Colvin, R.M., Witt, G.B., Lacey, J., 2016. Approaches to identifying stakeholders in environmental management: insights from practitioners to go beyond the 'usual suspects.' Land Use Policy 52, 266-276.

Corominas, L., Larsen, H., Flores-Alsina, X., Vanrolleghem, P., 2013. Including Life Cycle Assessment for decision-making in controlling wastewater nutrient removal systems. J. Environ. Manage. 128, 759-767. https://doi.org/10.1016/j.jenvman.2013.06.002

de Almeida, A.T., de Almeida, J.A., Costa, A.P.C.S., de Almeida-Filho, A.T., 2016. A new method for elicitation of criteria weights in additive models: Flexible and interactive tradeoff. Eur. J. Oper. Res. 250, 179-191.

DeFries, R., Nagendra, H., 2017. Ecosystem management as a wicked problem. Science 356, 265-270. https://doi.org/10.1126/science.aal1950

Delignette-Muller, M.L., Dutang, C., 2015. fitdistrplus: An R package for fitting distributions. J. Stat. Softw. 64, 1-34. 
Confidential manuscript submitted to Journal of Environmental Management; Harris-Lovett, Lienert, Sedlak

Dodds, W.K., Bouska, W.W., Eitzmann, J.L., Pilger, T.J., Pitts, K.L., Riley, A.J., Schloesser, J.T., Thornbrugh, D.J., 2008. Eutrophication of U.S. Freshwaters: Analysis of Potential Economic Damages [WWW Document]. https://doi.org/10.1021/es801217q

Dominguez, D., Gujer, W., 2006. Evolution of a wastewater treatment plant challenges traditional design concepts. Water Res. 40, 1389-1396. https://doi.org/10.1016/j.watres.2006.01.034

Dominguez, D., Truffer, B., Gujer, W., 2011. Tackling uncertainties in infrastructure sectors through strategic planning: The contribution of discursive approaches in the urban water sector. Water Policy 13, 299-316.

Dominguez, D., Worch, H., Markard, J., Truffer, B., Gujer, W., 2009. Closing the capability gap: strategic planning for the infrastructure sector. Calif. Manage. Rev. 51, 30-50.

Dublin San Ramon Services District, 2016. Dublin San Ramon Services District 2015 Urban Water Management Plan.

Dufrene, M., Legendre, P., 1997. Species assemblages and indicator species: the need for a flexible asymmetrical approach. Ecol. Monogr. 67, 345-366.

Durbach, I.N., Stewart, T.J., 2012. Modeling uncertainty in multi-criteria decision analysis. Eur. J. Oper. Res. 223, 1-14. https://doi.org/10.1016/j.ejor.2012.04.038

Eisenführ, F., Weber, M., Langer, T., 2010. Rational decision making. Springer, Berlin; London.

Ferguson, B.C., Frantzeskaki, N., Brown, R.R., 2013. A strategic program for transitioning to a Water Sensitive City. Landsc. Urban Plan. 117, 32-45. https://doi.org/10.1016/j.landurbplan.2013.04.016

Foley, J., de Haas, D., Hartley, K., Lant, P., 2010. Comprehensive life cycle inventories of alternative wastewater treatment systems. Water Res. 44, 1654-1666. https://doi.org/10.1016/j.watres.2009.11.031

Food and Drug Administration, 2012. FDA Drug Access Data Sheet, Bactrim: Sulfamethoxazole and trimethoprim DS tablets.

Fratini, C.F., Elle, M., Jensen, M.B., Mikkelsen, P.S., 2012. A conceptual framework for addressing complexity and unfolding transition dynamics when developing sustainable adaption strategies in urban water management. Water Sci. Technol. 66, 2393-2401. https://doi.org/10.2166/wst.2012.442

Fuchs, V.J., Mihelcic, J.R., Gierke, J.S., 2011. Life cycle assessment of vertical and horizontal flow constructed wetlands for wastewater treatment considering nitrogen and carbon greenhouse gas emissions. Water Res. 45, 2073-2081. https://doi.org/10.1016/j.watres.2010.12.021

Garrido-Baserba, M., Reif, R., Molinos-Senante, M., Larrea, L., Castillo, A., Verdaguer, M., Poch, M., 2016. Application of a multi-criteria decision model to select of design choices for WWTPs. Clean Technol. Environ. Policy 18, 1097-1109. https://doi.org/10.1007/s10098-016-1099-x

Gavin Simpson, 2016. permute: Functions for Generating Restricted Permutations of Data.

GHD, 2016. 2015 Urban Water Management Plan prepared for the City of Millbrae.

Gleick, P.H., 2000. A Look at Twenty-first Century Water Resources Development. Water Int. 25, 127 138. https://doi.org/10.1080/02508060008686804

Greening, L., Bernow, S., 2004. Design of coordinated energy and environmental policies: use of multicriteria decision-making. Energy Policy 32, 721-735.

Gregory, R., Failing, L., Higgins, P., 2006. Adaptive management and environmental decision making: A case study application to water use planning. Ecol. Econ. 58, 434-447. https://doi.org/10.1016/j.ecolecon.2005.07.020

Gregory, R., McDaniels, T., Fields, D., 2001. Decision Aiding, Not Dispute Resolution: Creating Insights through Structured Environmental Decisions. J. Policy Anal. Manage. 20, 415-432. https://doi.org/10.1002/pam.1001

Grimble, R., Wellard, K., 1997. Stakeholder methodologies in natural resource management: a review of principles, contexts, experiences and opportunities. Agric. Syst. 55, 173-193. 
Confidential manuscript submitted to Journal of Environmental Management; Harris-Lovett, Lienert, Sedlak

Hager, S.W., Schemel, L.E., 1992. Sources of nitrogen and phosphorus to Northern San Francisco Bay. Estuaries 15, 40-52. https://doi.org/10.2307/1352708

Hajkowicz, S., Collins, K., 2006. A Review of Multiple Criteria Analysis for Water Resource Planning and Management. Water Resour. Manag. 21, 1553-1566. https://doi.org/10.1007/s11269-0069112-5

Hajkowicz, S.A., 2008. Supporting multi-stakeholder environmental decisions. J. Environ. Manage. 88, 607-614. https://doi.org/10.1016/j.jenvman.2007.03.020

Hämäläinen, R.P., Alaja, S., 2008. The threat of weighting biases in environmental decision analysis. Ecol. Econ. 68, 556-569.

Harris-Lovett, S., Lienert, J. and Sedlak, S. 2018. Towards a New Paradigm of Urban Water Infrastructure: Identifying Goals and Strategies to Support Multi-Benefit Municipal Wastewater Treatment. Water 10.9, 1127.

Harris-Lovett, S., Sedlak, D. 2015. The History of Water Reuse in California. In Sustainable Water: Challenges and Solutions from California. Ed. Allison Lassiter. Berkeley: University of California Press.

Hauger, M.B., Rauch, W., Linde, J.J., Mikkelsen, P.S., 2002. Cost benefit risk - a concept for management of integrated urban wastewater systems? Water Sci. Technol. 45, 185-193.

HDR Consulting, 2017. Nutrients Regulatory Update.

Heberger, M., Cooley, H., Herrera, P., Gleick, P.H., Moore, E., 2009. The impacts of sea-level rise on the California coast. Calif. Clim. Change Cent. CEC-500-2009-024-F.

Heisler, J., Glibert, P., Burkholder, J., Anderson, D., Cochlan, W., Dennison, W., Gobler, C., Dortch, Q., Heil, C., Humphries, E., Lewitus, A., Magnien, R., Marshall, H., Sellner, K., Stockwell, D., Stoecker, D., Suddleson, M., 2008. Eutrophication and Harmful Algal Blooms: A Scientific Consensus. Harmful Algae 8, 3-13. https://doi.org/10.1016/j.hal.2008.08.006

Hendrickson, T.P., Nguyen, M.T., Sukardi, M., Miot, A., Horvath, A., Nelson, K.L., 2015. Life-cycle energy use and greenhouse gas emissions of a building-scale wastewater treatment and nonpotable reuse system. Environ. Sci. Technol. 49, 10303-10311.

Hermans, C., Erickson, J., Noordewier, T., Sheldon, A., Kline, M., 2007. Collaborative environmental planning in river management: An application of multicriteria decision analysis in the White River Watershed in Vermont. J. Environ. Manage. 84, 534-546. https://doi.org/10.1016/j.jenvman.2006.07.013

Howarth, R.W., 2008. Coastal nitrogen pollution: a review of sources and trends globally and regionally. Harmful Algae 8, 14-20.

Howarth, R.W., Anderson, D.B., Cloern, J.E., Elfring, C., Hopkinson, C.S., Lapointe, B., Maloney, T.J., Marcus, N., McGlathery, K., Sharpley, A.N., 2000. Issues in ecology: Nutrient pollution of coastal rivers, bays, and seas.

Howarth, R.W., Sharpley, A., Walker, D., 2002. Sources of nutrient pollution to coastal waters in the United States: Implications for achieving coastal water quality goals. Estuaries 25, 656-676.

Huang, I.B., Keisler, J., Linkov, I., 2011. Multi-criteria decision analysis in environmental sciences: Ten years of applications and trends. Sci. Total Environ. 409, 3578-3594. https://doi.org/10.1016/j.scitotenv.2011.06.022

Jasper, J.T., Jones, Z.L., Sharp, J.O., Sedlak, D.L., 2014a. Biotransformation of Trace Organic Contaminants in Open-Water Unit Process Treatment Wetlands. Environ. Sci. Technol. 48, 51365144. https://doi.org/10.1021/es500351e

Jasper, J.T., Jones, Z.L., Sharp, J.O., Sedlak, D.L., 2014b. Nitrate removal in shallow, open-water treatment wetlands. Environ. Sci. Technol. 48, 11512-11520. https://doi.org/10.1021/es502785t

Jasper, J.T., Nguyen, M.T., Jones, Z.L., Ismail, N.S., Sedlak, D.L., Sharp, J.O., Luthy, R.G., Horne, A.J., Nelson, K.L., 2013. Unit Process Wetlands for Removal of Trace Organic Contaminants and Pathogens from Municipal Wastewater Effluents. Environ. Eng. Sci. 30, 421-436. https://doi.org/10.1089/ees.2012.0239 
Confidential manuscript submitted to Journal of Environmental Management; Harris-Lovett, Lienert, Sedlak

Jasper, J.T., Sedlak, D.L., 2013. Phototransformation of Wastewater-Derived Trace Organic Contaminants in Open-Water Unit Process Treatment Wetlands. Environ. Sci. Technol. 47, 10781-10790. https://doi.org/10.1021/es304334w

Jenkins, R.R., Martinez, S.A., Palmer, K., Podolsky, M.J., 2003. The determinants of household recycling: a material-specific analysis of recycling program features and unit pricing. J. Environ. Econ. Manag. 45, 294-318. https://doi.org/10.1016/S0095-0696(02)00054-2

Jucherski, A., Nastawny, M., Walczowski, A., Jóźwiakowski, K., Gajewska, M., 2017. Assessment of the technological reliability of a hybrid constructed wetland for wastewater treatment in a mountain eco-tourist farm in Poland. Water Sci. Technol. 75, 2649-2658.

Kabir, G., Sadiq, R., Tesfamariam, S., 2014. A review of multi-criteria decision-making methods for infrastructure management. Struct. Infrastruct. Eng. 10, 1176-1210. https://doi.org/10.1080/15732479.2013.795978

Kang, D., Lansey, K., 2012. Multiperiod planning of water supply infrastructure based on scenario analysis. J. Water Resour. Plan. Manag. 140, 40-54.

Kangas, Kangas, A., Pekka, L., Pykäläinen, J., 2002. MCDM methods in strategic planning of forestry on state-owned lands in Finland: applications and experiences. J. Multi-Criteria Decis. Anal. 10, 257-271. https://doi.org/10.1002/mcda.306

Kavvada, O., Horvath, A., Stokes-Draut, J.R., Hendrickson, T.P., Eisenstein, W.A., Nelson, K.L., 2016. Assessing location and scale of urban nonpotable water reuse systems for life-cycle energy consumption and greenhouse gas emissions. Environ. Sci. Technol. 50, 13184-13194.

Keeney, R., 1992. Value-focused thinking: a path to creative decision making. Harvard University Press, Cambridge, MA.

Keeney, R.L., Raiffa, H., 1976. Decision with multiple objectives. Wiley, New York.

Kiker, G.A., Bridges, T.S., Varghese, A., Seager, T.P., Linkov, I., 2005. Application of multicriteria decision analysis in environmental decision making. Integr. Environ. Assess. Manag. 1, 95-108. https://doi.org/10.1897/IEAM_2004a-015.1

Kottemann, J.E., Davis, F.D., 1991. Decisional Conflict and User Acceptance of Multicriteria DecisionMaking Aids*. Decis. Sci. 22, 918-926. https://doi.org/10.1111/j.1540-5915.1991.tb00371.x

Kunz, N.C., Moran, C.J., Kastelle, T., 2013. Implementing an integrated approach to water management by matching problem complexity with management responses: a case study of a mine site water committee. J. Clean. Prod. 52, 362-373. https://doi.org/10.1016/j.jclepro.2013.03.018

Lahdelma, R., Salminen, P., Hokkanen, J., 2000. Using Multicriteria Methods in Environmental Planning and Management. Environ. Manage. 26, 595-605. https://doi.org/10.1007/s002670010118

Lai, V.S., Wong, B.K., Cheung, W., 2002. Group decision making in a multiple criteria environment: A case using the AHP in software selection. Eur. J. Oper. Res. 137, 134-144. https://doi.org/10.1016/S0377-2217(01)00084-4

Langhans, S., Reichert, P., Schuwirth, N., 2014. The method matters: A guide for indicator aggregation in ecological assessments. Ecol. Indic. 45, 494-507. https://doi.org/10.1016/j.ecolind.2014.05.014

Langhans, S.D., Lienert, J., 2016. Four Common Simplifications of Multi-Criteria Decision Analysis do not hold for River Rehabilitation. PLoS ONE 11. https://doi.org/10.1371/journal.pone.0150695

Larsen, T.A., Alder, A.C., Eggen, R.I., Maurer, M., Lienert, J., 2009. Source separation: will we see a paradigm shift in wastewater handling? Environ. Sci. Technol. 43, 6121-6125. http://dx.doi.org/10.1021/es803001r

Larsen, T.A., Gujer, W., 1997. The concept of sustainable urban water management. Water Sci. Technol. $35,3-10$.

Lichtenstein, S., Slovic, P., 2006. The construction of preference. Cambridge University Press.

Lienert, J., Larsen, T.A., 2009. High acceptance of urine source separation in seven European countries: a review. Environ. Sci. Technol. 44, 556-566.

Lienert, J., Larsen, T.A., 2007. Soft Paths in Wastewater Management: The Pros and Cons of Urine Source Separation. GAIA - Ecol. Perspect. Sci. Soc. 16, 280-288. 
Confidential manuscript submitted to Journal of Environmental Management; Harris-Lovett, Lienert, Sedlak

Lienert, J., Monstadt, J., Truffer, B., 2006. Future scenarios for a sustainable water sector: a case study from Switzerland. Environ. Sci. Technol. 40, 436-442.

Lienert, J., Schnetzer, F., Ingold, K., 2013. Stakeholder analysis combined with social network analysis provides fine-grained insights into water infrastructure planning processes. J. Environ. Manage. $125,134-148$.

Lienert, J., Scholten, L., Egger, C., Maurer, M., 2014. Structured decision-making for sustainable water infrastructure planning and four future scenarios. EURO J. Decis. Process. 1-34.

Linkov, I., Satterstrom, F.K., Kiker, G., Batchelor, C., Bridges, T., Ferguson, E., 2006. From comparative risk assessment to multi-criteria decision analysis and adaptive management: Recent developments and applications. Environ. Int. 32, 1072-1093.

Liu, Y., Gupta, H., Springer, E., Wagener, T., 2008. Linking science with environmental decision making: Experiences from an integrated modeling approach to supporting sustainable water resources management. Environ. Model. Softw. 23, 846-858. https://doi.org/10.1016/j.envsoft.2007.10.007

Livermore-Amador Valley Zone 7 Water Agency, 2016. Water Supply Evaluation Update: Water Supply Alternatives for the Livermore-Amador Valley.

Lund, L.., Horne, A.., Williams, A.., 1999. Estimating denitrification in a large constructed wetland using stable nitrogen isotope ratios. Ecol. Eng. 14, 67-76. https://doi.org/10.1016/S09258574(99)00020-8

Lyons, E., Zhang, P., Benn, T., Sharif, F., Li, K., Crittenden, J., Costanza, M., Chen, Y.S., 2009. Life cycle assessment of three water supply systems: importation, reclamation and desalination. Water Sci. Technol. Water Supply 9, 439-448. https://doi.org/10.2166/ws.2009.534

Maechler, Rousseeuw, Struyf, Hubert, Hornik, 2016. cluster: Cluster Analysis Basics and Extensions.

Mahmoud, M., Liu, Y., Hartmann, H., Stewart, S., Wagener, T., Semmens, D., Stewart, R., Gupta, H., Dominguez, D., Dominguez, F., others, 2009. A formal framework for scenario development in support of environmental decision-making. Environ. Model. Softw. 24, 798-808.

Mander, Ü., Dotro, G., Ebie, Y., Towprayoon, S., Chiemchaisri, C., Nogueira, S.F., Jamsranjav, B., Kasak, K., Truu, J., Tournebize, J., Mitsch, W.J., 2014. Greenhouse gas emission in constructed wetlands for wastewater treatment: A review. Ecol. Eng., Wetland Restoration-Challenges and Opportunities 66, 19-35. https://doi.org/10.1016/j.ecoleng.2013.12.006

Mardle, S., Pascoe, S., Herrero, I., 2004. Management Objective Importance in Fisheries: An Evaluation Using the Analytic Hierarchy Process (AHP). Environ. Manage. 33, 1-11. https://doi.org/10.1007/s00267-003-3070-y

Marttunen, M., Belton, V., Lienert, J., 2018. Are objectives hierarchy related biases observed in practice? A meta-analysis of environmental and energy applications of Multi-Criteria Decision Analysis. Eur. J. Oper. Res. 265, 178-194.

Marttunen, M., Hämäläinen, R.P., 2008. The Decision Analysis Interview Approach in the Collaborative Management of a Large Regulated Water Course. Environ. Manage. 42, 1026. https://doi.org/10.1007/s00267-008-9200-9

Marttunen, M., Lienert, J., Belton, V., 2017. Structuring problems for Multi-Criteria Decision Analysis in practice: A literature review of method combinations. Eur. J. Oper. Res. 263, 1-17.

Marttunen, M., Mustajoki, J., Dufva, M., Karjalainen, T.P., 2015. How to design and realize participation of stakeholders in MCDA processes? A framework for selecting an appropriate approach. EURO J. Decis. Process. 3, 187-214.

Massey, A.P., Wallace, W.A., 1996. Understanding and facilitating group problem structuring and formulation: Mental representations, interaction, and representation aids. Decis. Support Syst., DSS on Model Formulation 17, 253-274. https://doi.org/10.1016/0167-9236(96)00004-8

Matsatsinis, N.F., Samaras, A.P., 2001. MCDA and preference disaggregation in group decision support systems. Eur. J. Oper. Res. 130, 414-429. https://doi.org/10.1016/S0377-2217(00)00038-2 
Confidential manuscript submitted to Journal of Environmental Management; Harris-Lovett, Lienert, Sedlak

Mays, N., Pope, C., Popay, J., 2005. Systematically reviewing qualitative and quantitative evidence to inform management and policy-making in the health field. J. Health Serv. Res. Policy 10, 6-20. https://doi.org/10.1258/1355819054308576

McCune, B., Grace, J., 2002. Analysis of Ecological Communities. Mjm Software Design, United States.

McDaniels, T.L., Gregory, R.S., Fields, D., 1999. Democratizing Risk Management: Successful Public Involvement in Local Water Management Decisions. Risk Anal. 19, 497-510. https://doi.org/10.1111/j.1539-6924.1999.tb00424.x

Mendoza, G.A., Martins, H., 2006. Multi-criteria decision analysis in natural resource management: a critical review of methods and new modelling paradigms. For. Ecol. Manag. 230, 1-22.

Mitchell, R.K., Agle, B.R., Wood, D.J., 1997. Toward a theory of stakeholder identification and salience: Defining the principle of who and what really counts. Acad. Manage. Rev. 22, 853-886.

Munda, G., Nijkamp, P. and Rietveld, P., 1994. Qualitative multicriteria evaluation for environmental management. Ecological Economics, 10(2), pp.97-112.

Mustajoki, J., Hämäläinen, R.P., Salo, A., 2005. Decision Support by Interval SMART/SWINGIncorporating Imprecision in the SMART and SWING Methods. Decis. Sci. 36, 317-339. https://doi.org/10.1111/j.1540-5414.2005.00075.x

Mutikanga, H.E., Sharma, S.K., Vairavamoorthy, K., 2011. Multi-criteria decision analysis: a strategic planning tool for water loss management. Water Resour. Manag. 25, 3947-3969.

National Science Foundation's Engineering Research Center for Reinventing the Nation's Urban Water Infrastructure, 2015. Technology Diffusion Workshop on Open Water Unit Process Wetlands.

Nederhof, A.J., 1985. Methods of coping with social desirability bias: A review. Eur. J. Soc. Psychol. 15, 263-280.

Neuwirth, E., 2014. RColorBrewer: ColorBrewer Palettes.

Northwest EcoBuilding Guild, 2014. 2014 EcoToilet Incentive in Falmouth Massachusetts [WWW Document]. URL http://www.ecobuilding.org/code-innovations/policy-profiles/2014-ecotoiletincentive-in-falmouth-ma (accessed 9.13.17).

Novick, E., Senn, D., 2014. External Nutrient Loads to San Francisco Bay (No. Contribution No. 704). San Francisco Estuary Institute, Richmond, CA.

Oksanen, J., Blanchett, G., Michael Friendly, Roeland Kindt, Pierre Legendre, Dan McGlinn, Peter Minchin, RB O’Hara, Gavin Simpson, Peter Solymos, M. Henry Stevens, Eduard Szoecs, Helene Wagner, 2017. vegan: Community Ecology Package.

Oro Loma Sanitary District, n.d. Oro Loma Ecotone Project: Building Climate Change Resiliency Along the Bay Shoreline with Green Infrastructure and Treated Wastewater.

Pan, T., Zhu, X.-D., Ye, Y.-P., 2011. Estimate of life-cycle greenhouse gas emissions from a vertical subsurface flow constructed wetland and conventional wastewater treatment plants: A case study in China. Ecol. Eng. 37, 248-254. https://doi.org/10.1016/j.ecoleng.2010.11.014

Pasqualino, J.C., Meneses, M., Castells, F., 2011. Life Cycle Assessment of Urban Wastewater Reclamation and Reuse Alternatives. J. Ind. Ecol. 15, 49-63. https://doi.org/10.1111/j.15309290.2010.00293.x

Payne, J.W., Bettman, J.R., Johnson, E.J., 1992. Behavioral decision research: A constructive processing perspective. Annu. Rev. Psychol. 43, 87-131.

Peacock, B., 1996. Energy and Cost Required to Lift or Pressurize Water (No. Pub IG6-96). University of California Cooperative Extension, Tulare County.

Pearson, L.J., Coggan, A., Proctor, W., Smith, T.F., 2010. A sustainable decision support framework for urban water management. Water Resour. Manag. 24, 363-376.

Pereira, A.G., Munda, G., Paruccini, M., 1994. Generating alternatives for siting retail and service facilities using genetic algorithms and multiple criteria decision techniques. J. Retail. Consum. Serv. 1, 40-47.

Pérez-González, A., Urtiaga, A.M., Ibáñez, R., Ortiz, I., 2012. State of the art and review on the treatment technologies of water reverse osmosis concentrates. Water Res. 46, 267-283. 
Confidential manuscript submitted to Journal of Environmental Management; Harris-Lovett, Lienert, Sedlak

Peterson, G.D., Cumming, G.S., Carpenter, S.R., 2003. Scenario Planning: a Tool for Conservation in an Uncertain World. Conserv. Biol. 17, 358-366. https://doi.org/10.1046/j.1523-1739.2003.01491.x

Pope, C. and Mays, N., 1995. Qualitative research: reaching the parts other methods cannot reach: an introduction to qualitative methods in health and health services research. Bmj, 311(6996), pp.4245.

Pöyhönen, M., Hämäläinen, R.P., 2000. There is hope in attribute weighting. INFOR Inf. Syst. Oper. Res. $38,272-282$.

R Core Team, 2013. R: A language and environment for statistical computing. R Foundation for Statistical Computing, Vienna, Austria.

Racoviceanu, A., Karney, B.W., Kennedy, C.A., Colombo, 2007. Life-Cycle Energy Use and Greenhouse Gas Emissions Inventory for Water Treatment Systems. J. Infrastruct. Syst. 13, 261-270. https://doi.org/10.1061/(ASCE)1076-0342(2007)13:4(261)

Radjenović, J., Petrović, M., Ventura, F., Barceló, D., 2008. Rejection of pharmaceuticals in nanofiltration and reverse osmosis membrane drinking water treatment. Water Res. 42, 36013610. https://doi.org/10.1016/j.watres.2008.05.020

Reed, M.S., 2008. Stakeholder participation for environmental management: a literature review. Biol. Conserv. 141, 2417-2431.

Reed, M.S., Graves, A., Dandy, N., Posthumus, H., Hubacek, K., Morris, J., Prell, C., Quinn, C.H., Stringer, L.C., 2009. Who's in and why? A typology of stakeholder analysis methods for natural resource management. J. Environ. Manage. 90, 1933-1949. https://doi.org/10.1016/j.jenvman.2009.01.001

Reichert, P., Langhans, S.D., Lienert, J., Schuwirth, N., 2015. The conceptual foundation of environmental decision support. J. Environ. Manage. 154, 316-332.

Reichert, P., Schuwirth, N., Langhans, S., 2013. Constructing, evaluating and visualizing value and utility functions for decision support. Environ. Model. Softw. 46, 283-291.

Rose, C., Parker, A., Jefferson, B., Cartmell, E., 2015. The characterization of feces and urine: a review of the literature to inform advanced treatment technology. Crit. Rev. Environ. Sci. Technol. 45, $1827-1879$.

Rosenblum, E., 1999. Selection and implementation of nonpotable water recycling in "Silicon Valley" (San Jose area) California. Water Sci. Technol. 40, 51-57. https://doi.org/10.1016/S02731223(99)00574-0

San Francisco Bay Nutrient Management Strategy, 2016. Charter of the San Francisco Bay Nutrient Management Strategy: Purpose, Organization, and Governance of the Nutrient Management Strategy.

San Francisco Bay Regional Water Quality Control Board, 2014. Waste Discharge Requirements for Nutrients from Municipal Wastewater Discharges to San Francisco Bay (No. Order No. R2-20140014). San Francisco Bay Regional Water Quality Control Board.

San Francisco Bay Regional Water Quality Control Board, 2013. Revised Tentative Order No. R2-20130011 NPDES No. CA0038318.

San Francisco Public Utilities Commission, 2016. 2015 Urban Water Management Plan for the City and County of San Francisco.

Santa Clara Valley Water District and City of San Jose, 2014. South Bay Water Recycling Strategic and Master Planning Report.

Schoemaker, P.J.H., 1995. Scenario Planning: A Tool for Strategic Thinking. Sloan Manag. Rev. Camb. Mass 36, 25-40.

Scholten, L., Maurer, M., Lienert, J., 2017. Comparing multi-criteria decision analysis and integrated assessment to support long-term water supply planning. PLoS ONE 12. https://doi.org/10.1371/journal.pone.0176663 
Confidential manuscript submitted to Journal of Environmental Management; Harris-Lovett, Lienert, Sedlak

Scholten, L., Scheidegger, A., Reichert, P., Maurer, M., 2013. Combining expert knowledge and local data for improved service life modeling of water supply networks. Environ. Model. Softw. 42, 116. https://doi.org/10.1016/j.envsoft.2012.11.013

Scholten, L., Schuwirth, N., Reichert, P., Lienert, J., 2015. Tackling uncertainty in multi-criteria decision analysis-An application to water supply infrastructure planning. Eur. J. Oper. Res. 242, 243-260. http://dx.doi.org/10.1016/j.ejor.2014.09.044

Schuwirth, N., Reichert, P., Lienert, J., 2012. Methodological aspects of multi-criteria decision analysis for policy support: A case study on pharmaceutical removal from hospital wastewater. Eur. J. Oper. Res. 220, 472-483. https://doi.org/10.1016/j.ejor.2012.01.055

Scott, C.A., Bailey, C.J., Marra, R.P., Woods, G.J., Ormerod, K.J., Lansey, K., 2012. Scenario planning to address critical uncertainties for robust and resilient water-wastewater infrastructures under conditions of water scarcity and rapid development. Water 4, 848-868.

Soltani, A., Hewage, K., Reza, B., Sadiq, R., 2015. Multiple stakeholders in multi-criteria decisionmaking in the context of municipal solid waste management: a review. Waste Manag. 35, 318328.

Starkl, M., Brunner, N., Flögl, W., Wimmer, J., 2009. Design of an institutional decision-making process: The case of urban water management. J. Environ. Manage. 90, 1030-1042. https://doi.org/10.1016/j.jenvman.2008.03.012

State of California Employment Development Department, 2015. Regional Economic Analysis Profile: San Francisco Bay Area Economic Market.

Stokes, J.R., Horvath, A., 2009. Energy and Air Emission Effects of Water Supply. Environ. Sci. Technol. 43, 2680-2687. https://doi.org/10.1021/es801802h

Störmer, E., Truffer, B., 2009. Strategic decision making in infrastructure sectors: participatory foresight and strategic planning for sustainable sanitation. Geogr. Helvetica 64, 73-80.

Störmer, E., Truffer, B., Dominguez, D., Gujer, W., Herlyn, A., Hiessl, H., Kastenholz, H., Klinke, A., Markard, J., Maurer, M., others, 2009. The exploratory analysis of trade-offs in strategic planning: Lessons from Regional Infrastructure Foresight. Technol. Forecast. Soc. Change 76, 1150-1162.

Sutula, M., Senn, D., 2015. Scientific Basis to Assess the Effects of Nutrients on San Francisco Bay Beneficial Uses (Technical Report 864 No. Contract 11-151-120). Prepared for the San Francisco Bay Regional Water Quality Control Board.

Tarpeh, W.A., Udert, K.M., Nelson, K.L., 2017. Comparing Ion Exchange Adsorbents for Nitrogen Recovery from Source-Separated Urine. Environ. Sci. Technol. 51, 2373-2381. https://doi.org/10.1021/acs.est.6b05816

Tchobanoglous, G., Raucher, R., 2014. The Opportunities and Economics of Direct Potable Reuse (No. WRRF-14-08). WateReuse Research Foundation, Alexandria, VA.

Thornton, J., Harding, W., Dent, M., Hart, R., Lin, H., Rast, C., Rast, W., Ryding, S., Slawski, T., 2013. Eutrophication as a 'wicked' problem. Lakes Reserv. Res. Manag. 18, 298-316. https://doi.org/10.1111//re.12044

Tilley, E., Günther, I., 2016. The Impact of Conditional Cash Transfer on Toilet Use in eThekwini, South Africa. Sustainability 8, 1070.

Trautmann, H., Steuer, D., Mersmann, O., Bornkamp, B., 2014. truncnorm: Truncated normal distribution.

Truffer, B., Störmer, E., Maurer, M., Ruef, A., 2010. Local strategic planning processes and sustainability transitions in infrastructure sectors. Environ. Policy Gov. 20, 258-269.

Umar, M., Roddick, F., Fan, L., 2015. Recent advancements in the treatment of municipal wastewater reverse osmosis concentrate-an overview. Crit. Rev. Environ. Sci. Technol. 45, 193-248.

U.S. Bureau of Labor Statistics, Western Information Office, 2017. Average Energy Prices, San Francisco-Oakland-San Jose [WWW Document]. URL https://www.bls.gov/regions/west/newsrelease/averageenergyprices_sanfrancisco.htm (accessed 9.13.17). 
Confidential manuscript submitted to Journal of Environmental Management; Harris-Lovett, Lienert, Sedlak

US EPA, O., 2015. Greenhouse Gas Equivalencies Calculator [WWW Document]. US EPA. URL https://www.epa.gov/energy/greenhouse-gas-equivalencies-calculator (accessed 7.5.17).

Van Dolah, F.M., 2000. Marine algal toxins: origins, health effects, and their increased occurrence. Environ. Health Perspect. 108, 133.

Vazquez-Montiel, O., Horan, N.J., Mara, D.D., 1996. Management of domestic wastewater for reuse in irrigation. Water Sci. Technol., Wastewater Reclamation and Reuse 1995 33, 355-362. https://doi.org/10.1016/0273-1223(96)00438-6

Vos, J.F.J., Achterkamp, M.C., 2006. Stakeholder identification in innovation projects: Going beyond classification. Eur. J. Innov. Manag. 9, 161-178. https://doi.org/10.1108/14601060610663550

Vymazal, J., 2010. Constructed Wetlands for Wastewater Treatment. Water 2, 530-549. https://doi.org/10.3390/w2030530

Wankel, S.D., Carol, K., Chris, F.A., Paytan, A., 2005. Nitrogen sources and cycling in the San Francisco Bay Estuary: A nitrate dual isotopic composition approach. AGU Fall Meet. Abstr. 1, 0982.

WEST Web [WWW Document], n.d. URL http://west.berkeley.edu/tool.php (accessed 10.30.17).

Wickham, H., 2011. The split-apply-combine strategy for data analysis. J. Stat. Softw. 40, 1-29.

Wilkinson, A., Kupers, R., 2014. The Essence of Scenarios: Learning from the Shell Experience. Amsterdam University Press, Amsterdam.

Wren, I., 2017. Treatment Wetlands for Nutrient Removal from Bay Area Wastewater Facilities: Screening Level Opportunities and Constraints Analysis - Draft Report. San Francisco Bay Nutrient Management Strategy, Oakland, CA.

Wright, G., Goodwin, P., 2009. Decision making and planning under low levels of predictability: Enhancing the scenario method. Int. J. Forecast., Special section: Decision making and planning under low levels of predictability 25, 813-825. https://doi.org/10.1016/j.ijforecast.2009.05.019

Zahir, S., 1999. Clusters in a group: Decision making in the vector space formulation of the analytic hierarchy process. Eur. J. Oper. Res. 112, 620-634.

Zheng, J., Egger, C., Lienert, J., 2016. A scenario-based MCDA framework for wastewater infrastructure planning under uncertainty. J. Environ. Manage. 183, 895-908.

Zuur, A., Ieno, E., Smith, G., 2007. Analyzing Ecological Data. Springer Science+Business Media, New York. 
Confidential manuscript submitted to Journal of Environmental Management; Harris-Lovett, Lienert, Sedlak 